\title{
A Simulation and Validation of CLM during Freeze-Thaw on the Tibetan Plateau
}

\author{
Xuewei Fang, ${ }^{1,2}$ Siqiong Luo, ${ }^{1}$ Shihua Lyu, ${ }^{1,3}$ Boli Chen, ${ }^{4}$ Yu Zhang, \\ Di Ma, ${ }^{1}$ and Yan Chang ${ }^{1}$ \\ ${ }^{1}$ Key Laboratory of Land Surface Process and Climate Change in Cold and Arid Regions, \\ Cold and Arid Regions Environment Research Institute, Chinese Academy of Sciences, Lanzhou 730000, China \\ ${ }^{2}$ University of the Chinese Academy of Sciences, Beijing 100049, China \\ ${ }^{3}$ Chengdu University of Information Technology, Chengdu 610225, China \\ ${ }^{4}$ Changzhou Meteorological Administration, Changzhou 213000, China \\ Correspondence should be addressed to Siqiong Luo; lsq@lzb.ac.cn
}

Received 21 December 2015; Revised 7 March 2016; Accepted 12 April 2016

Academic Editor: Xiao-Ming Hu

Copyright (C) 2016 Xuewei Fang et al. This is an open access article distributed under the Creative Commons Attribution License, which permits unrestricted use, distribution, and reproduction in any medium, provided the original work is properly cited.

\begin{abstract}
The applicability of a new soil hydraulic property of frozen soil scheme applied in Community Land Model 4.5 (CLM4.5), in conjunction with an impedance factor for the presence of soil ice, was validated through two offline numerical simulations conducted at Madoi (GS) and Zoige (ZS) on the Tibetan Plateau (TP). Sensitivity analysis was conducted via replacing the new soil hydraulic property scheme in CLM4.5 by the old one, using default CLM4.5 runs as reference. Results indicated that the new parameterization scheme ameliorated the surface dry biases at ZS but enlarged the wet biases which existed at GS site due to ignoring the gravel effect. The wetter surface condition in CLM4.5 also leads to a warmer surface soil temperature because of the greater heat capacity of liquid water. In addition, the combined impact of new soil hydraulic property schemes and the ice impedance function on the simulated soil moisture lead to the more reasonable simulation of the starting dates of freeze-thaw cycle, especially at the thawing stage. The improvements also lead to the more reasonable turbulent fluxes simulations. Meanwhile, the decreased snow cover fraction in CLM4.5 resulted in a lower albedo, which tended to increase net surface radiation compared to previous versions. Further optimizing is needed to take the gravel into account in the numerical description of thermal-hydrological interactions.
\end{abstract}

\section{Introduction}

Land surfaces, by affecting water and energy flows between the ground and the atmosphere, have a significant impact on weather forecasting as well as climate change. At present, the importance of land surface processes is widely recognized [1-7]. Meanwhile, in recent years, due to the complexity of land surface processes and the limitation of observations, the land surface models have become the major tool for landatmosphere interaction studies [6, 8-11].

The soil is the main body of land surface processes, connecting the earth spheres. The soil freeze-thaw process is an important parameter in the land surface and atmospheric modeling. The variations of soil temperature and soil moisture are indicators of frozen soil. Owing to the great gap of thermal conductivity and thermal capacity between liquid water and ice, the accuracy of simulated soil moisture can directly affect the calculation of thermal properties and thermal conductivities during freezing-thawing period. Meanwhile, the phase transition of soil moisture spends much of the energy exchanged between the atmosphere and the soil. The energy liberation and the energy absorption during the period change the distribution characteristics of ground temperature and also the pattern of energy. The soil temperature and soil moisture simulations should be considered prior to the assessment of land surface model performance.

The Tibetan Plateau (TP), which is characterized by flat topography and high elevation, plays an essential role in atmospheric circulation $[12,13]$, extreme weather in the 
Eastern Asia region [14-16], and even the global climate $[17,18]$. With large amounts of year-round permafrost and seasonal frozen soil coverage, the TP also has its unique position in land surface process. In seasonal frozen soil area on the TP, the energy release and absorption during the freezingthawing cycle of soil lead to the redistribution of energy and water between the ground and the atmosphere. It could change the surface albedo, the thermal and water properties of soil, the ground evaporation, and vegetation conditions. However, at present, compared with other regions, relatively fewer studies considered land surface process on the TP due to its harsh natural conditions. But the complex mechanisms of physical and chemical changes during freezing-thawing cycle on the TP, including the energy transfer, phase changes, and salt accumulation $[19,20]$, are not accounted for during numerical simulation. Deep researches of land surface processes on the TP region and their climatic effects are critical for further understanding of the East-Asian atmospheric circulation as well as global climate changes [1, 21-23].

The Community Land Model (CLM) is one of the most widely used land surface models in the world. Many previous works have confirmed its simulation ability in different regions [24-26]. The numerical expression of land surface processes determines the model performance. Based on biases in carbon cycle simulated by Community Climate System Model (CCSM4), Swenson et al. attribute them to the excessively dry soils simulation in permafrost regions partly. By replacing the dependence on total water content with liquid water content only, they modified the calculation of the hydraulic properties of frozen soil. They also incorporated an ice impedance function. The CLM adopted this modification and applied it to the latest version CLM4.5. Although Swenson et al. have demonstrated the improvement of soil moisture simulation in high-latitude permafrost area, they mostly focused on the accompanied improvement on the biogeochemical cycle simulation, such as gross primary production, net primary production, and vegetation carbon storage in permafrost regions. The applicability of the modified formulation and its possible effect on the soil temperature, soil moisture, and energy flux components during freeze-thaw cycle for the seasonal frozen soil region on the TP are ambiguous. Based on the significant impact of the soil mechanical components on the hydrothermal properties [6], this study mainly aims to assess the performance of the modified scheme in CLM4.5 during freeze-thaw cycle on the TP at two sites with entirely different soil textures via sensitivity analysis, using the default CLM4.5 runs as reference. This work can demonstrate the specific improvements of the formula in terms of energy fluxes and hydrothermal circulation in CLM4.5 during freeze-thaw period on the TP and also detect the existing inadequacies, thus providing a basis for model development in the future.

\section{Method}

2.1. Model Descriptions. CLM simulates the partitioning of mass and energy from the atmosphere, redistributes the mass and energy of the land surface, and then exports the fresh water and heat to the oceans [25]. It is the land component of the Community Climate System Model (CCSM) and the Community Earth System Model (CESM) [27]. CLM4.5 is an upgrade of CLM4.0. The biogeophysical processes in CLM4.0 include solar and longwave radiation interactions with the vegetation canopy and soil; momentum and turbulent fluxes from canopy and soil; heat transfer in soil and snow; hydrology of canopy, soil, and snow; and stomatal physiology and photo synthesis [27]. The detailed description of how these processes are parameterized can be found in the CLM4.0 Technical Description [28]. Main parameterizations revised in CLM4.5 include new hydraulic properties of frozen soils and the introduction of an ice impedance function [24]; a new snow cover fraction parameterization [25]; a completely revised lake model [29]; a revised canopy radiation scheme; and revisions to photosynthetic parameters [30]. In addition, compared to CLM4.0, CLM4.5 uses U.S. Geological Survey (USGS) global data, including 25 kinds of functional types (PFT), in 30-second intervals and 17 kinds of soil types from the Food and Agriculture Organization (FAO) and the State Soil Geographic (STATSGO) dataset that determine the soil thermal and hydrological properties. Biogeophysical processes in CLM are simulated for each subgrid land unit, column, and plant PFT independently and each subgrid unit maintains its own prognostic variables. Detailed information can be found in the Technical Description of the CLM4.5 published by the National Center for Atmospheric Research (NCAR) [31]. The performance of previous versions of CLMs has been confirmed on the TP $[10,19,20,32-34]$.

2.2. Theory. CLM uses Darcy's law to describe the vertical flux of water, which depends on the hydraulic conductivity $k$ and the soil matric potential $\psi$. Meanwhile, both of the two values are functions of soil moisture content. They are expressed as

$$
\begin{aligned}
& k=k_{\text {sat }}\left(\frac{\theta}{\phi}\right)^{2 B+3}, \\
& \psi=\psi_{\text {sat }}\left(\frac{\theta}{\phi}\right)^{-B},
\end{aligned}
$$

where $\theta$ is the volumetric soil moisture content $\left(\mathrm{mm}^{3} \mathrm{~mm}^{-3}\right)$, $\phi$ is the porosity of soil, $k_{\text {sat }}$ is the saturated hydraulic conductivity $\left(\mathrm{mm} \mathrm{s}^{-1}\right), \psi_{\text {sat }}$ is the saturated soil matric potential $(\mathrm{mm})$, and $B$ is based on soil texture $[24,31]$.

However, the calculation of soil hydraulic properties of frozen soils in CLM4.0 depends on the total water content $\left(\theta=\theta_{\text {liq }}+\theta_{\text {ice }}\right)$. Based on this calculation, the hydraulic properties of soil would not respond to the phase changes of soil water directly. The gradient of soil matric potential would be failure to couple to the soil thermal gradient and the observed migration of water towards a freezing front $[24,35]$.

In CLM4.5, the calculation of the hydraulic properties of frozen soils was modified by replacing their dependence on total water content with liquid water content only $\left(\theta=\theta_{\text {liq }}\right)$. Meanwhile, an ice impedance function $f_{\text {frz }}$ was also incorporated. The power-law formulation effectively increased the consistency between soil water state and water table position 
and allows for a perched water table above icy permafrost ground [24]. The formulations are presented as follows:

$$
\begin{aligned}
k & =\left(1-f_{\text {frz }}\right) k_{\text {sat }}\left(\frac{\theta}{\phi}\right)^{2 B+3}, \\
f_{\text {frz }} & =\frac{\exp \left[-\alpha\left(1-w_{\text {ice }} /\left(w_{\text {liq }}+w_{\text {ice }}\right)\right)\right]-\exp (-\alpha)}{1-\exp (-\alpha)},
\end{aligned}
$$

where $w_{\text {liq }}$ and $w_{\text {ice }}$ are the liquid and solid water contents of the top soil layer and $\alpha$ is constant which is defined as 3 in the model. The dependence of $f_{\text {frz }}$ on $w_{\text {liq }}$ limits the maximum value to less than 1 due to the presence of supercooled liquid water [24]. $f_{\text {frz }}$ is close to 1 on the complete stage then rapidly decreases while melting begins. Thus it accelerates the infiltration rates.

2.3. Sites Description. Simulations were conducted at two typical sites on the TP (Figure 1). Madoi $\left(35^{\circ} 01^{\prime} \mathrm{N}, 97^{\circ} 39^{\prime} \mathrm{E}\right.$, altitude $4272 \mathrm{~m}$ ) site is situated near the Lake Gyaring and the Lake Ngoring on the eastern part of TP. It locates in the seasonal frozen soil region and the climate classification is "cold and semiarid continental." According to the data from China National Climate Center, the average temperature from 1953 to 2012 is $-3.7^{\circ} \mathrm{C}$ and the annual mean precipitation is $350 \mathrm{~mm}$. The land surface is covered with alpine steppe and the soil contains large amounts of gravel. Zoige grassland $\left(33^{\circ} 89^{\prime} \mathrm{N}, 102^{\circ} 14^{\prime} \mathrm{E}\right.$, altitude $\left.3,423 \mathrm{~m}\right)$ locates in the Gannan Tibetan Autonomous Prefecture, Gansu Province, China. It is situated in the eastern TP. Generally, the climate at this site is cold and damp with wet mild summers and dry cold winters. The annual mean temperature from 1981 to 2010 is $1.9^{\circ} \mathrm{C}$ and the annual mean precipitation value is $593 \mathrm{~mm}$ according to the climate data measured at a meteorological station $\left(34^{\circ} 00^{\prime} \mathrm{N}, 102^{\circ} 08^{\prime} \mathrm{E}\right.$, altitude $\left.3,471 \mathrm{~m}\right)$ located approximately $14 \mathrm{~km}$ north of the Zoige grassland site. The grassland is dominated by Cyperaceae and Gramineae with an average height of about $0.2 \mathrm{~m} \mathrm{[36].} \mathrm{The} \mathrm{topography} \mathrm{is}$ flat and homogenous and the soil is silt clay loam composed of $29.8 \%$ sand, $66.7 \%$ silt, and $3.5 \%$ clay in the top $40 \mathrm{~cm} \mathrm{[36].}$

2.4. Field Measurements. The observation site, Grass Station (GS, $34^{\circ} 54^{\prime} \mathrm{N}, 97^{\circ} 33^{\prime} \mathrm{E}$ ) at Madoi, is located on the alpine grass on the west side of Ngoring Lake with a distance of $1.7 \mathrm{~km}$ to lake. The Zoige Grassland Station $\left(\mathrm{ZS}, 33^{\circ} 89^{\prime} \mathrm{N}, 102^{\circ} 14^{\prime} \mathrm{E}\right)$ is located in an alpine meadow grassland.

At GS site, the sensible heat flux and latent heat flux were measured with the eddy covariance system (EC), consisting of a three-dimensional sonic anemometer (CSAT3, Campbell Scientific, Inc.) and an open-path $\mathrm{CO}_{2} / \mathrm{H}_{2} \mathrm{O}$ infrared gas analyzer (IRGA; LI 7500, LI-COR, Inc.). The eddy covariance system was mounted at a height of $3.2 \mathrm{~m}$ above the land surface, and the sensor signals were recorded by a data logger (CR3000, Campbell Scientific, Inc.) at a 10-Hz frequency. The incoming and outgoing shortwave and longwave radiation were measured with a net radiometer (CNR-1/CNR-4, Kipp and Zonen) at $1.5 \mathrm{~m}$ above the ground, respectively. Besides, the soil water content and temperature were measured at soil depths of $0.05,0.10,0.20,0.40$, and $0.80 \mathrm{~m}$ with CS616

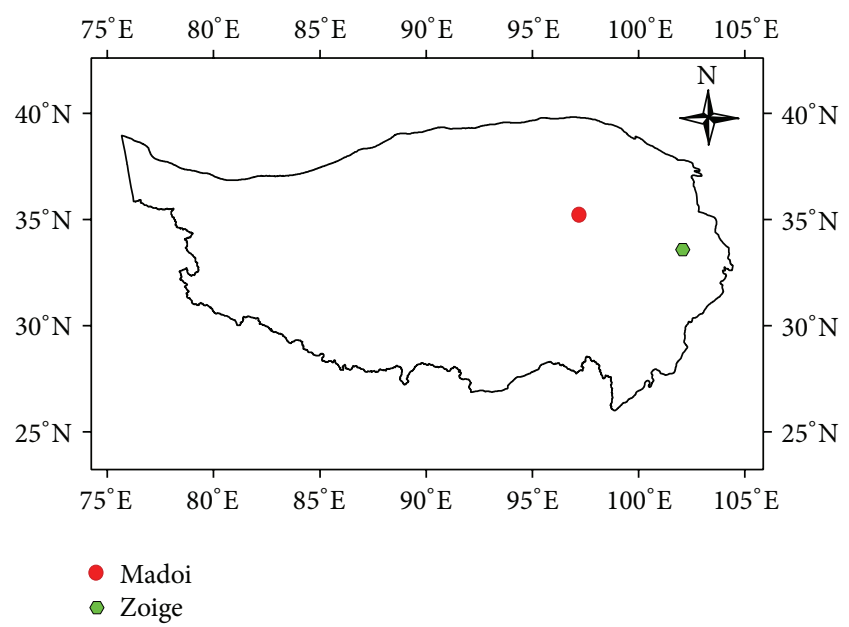

Figure 1: The Tibetan Plateau (TP), the locations of the Madoi site and the Zoige site.

and 109L, respectively (Campbell Scientific, Inc.). The air temperature and relative humidity sensors (HMP-45C) were also installed at a height of $3.2 \mathrm{~m}$. Precipitation was measured with a weighing gauge (T200B, Geonor, Norway). Soil heat flux was measured using heat flux plates (HPF01) buried at 5 to $10 \mathrm{~cm}$.

The EddyPro flux analysis software was used for data corrections in the postprocessing of $10 \mathrm{~Hz}$ EC data. Corrections such as time lag compensation spike and trend remove and coordinate rotation were also applied to the original data. Meanwhile, the raw virtual air temperature was also converted to air temperature. The water vapor fluxes were also amended using Webb-Pearman-Leuning (WPL) density correction [37].

At ZS site, the sensible heat flux and latent flux were also measured with the EC, consisting of a three-dimensional sonic anemometer (CSAT3, Campbell Scientific, Inc., Logan, UT, USA) and an open-path fast response infrared gas analyzer (LI-7500, LI-COR Biosciences Inc., Lincoln, NE, USA). Separation distance between the gas analyzer and sonic anemometer sensors was $0.15 \mathrm{~m}$. Both sensors were mounted $3.15 \mathrm{~m}$ above the soil surface. The air temperature and relative humidity sensor (HMP-45C, Vaisala, Helsinki, Finland) was also installed at the same height, which was used for correction of flux measurements for density effects due to heat and water vapor transfer. Similar to the measurements conducted at GS, signals from EC instrumentation were also recorded at rates of $10 \mathrm{~Hz}$, and the raw data were stored in a CR3000 data logger (Campbell Scientific, Inc.). Net radiation $\left(R_{n}\right)$ was measured at $1.5 \mathrm{~m}$ height with a four-component net radiometer (CNR-1, Kipp and Zonen, Delft, Netherlands). Precipitation was also measured with a weighing gauge (T200B, Geonor, Norway). Soil temperature and soil volumetric water content were measured at five layers $(5,10,20,40$, and $80 \mathrm{~cm}$ depths) with CS107 temperature probes (Campbell Scientific, Inc.) and CS616 timedomain reflectometer (TDR) probes (Campbell Scientific, Inc.), respectively. Soil heat flux was measured using heat flux 


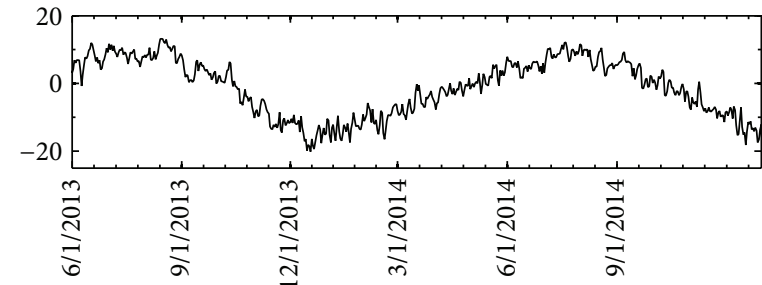

(a1)

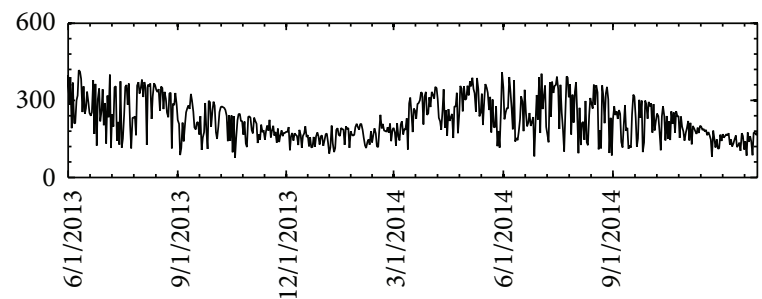

(b1)

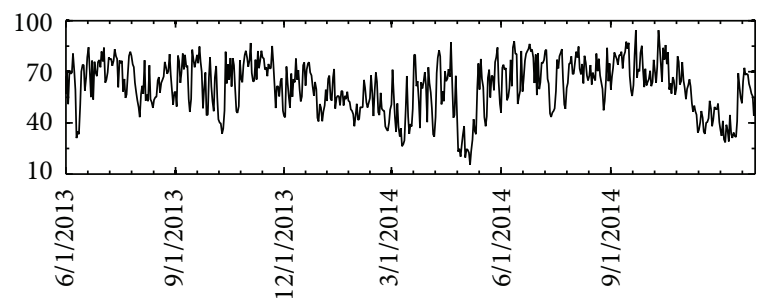

(c1)

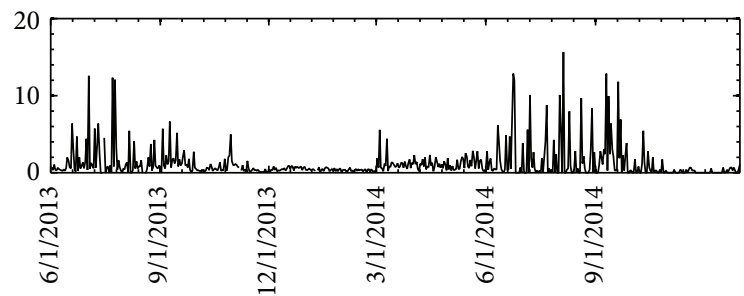

(d1)

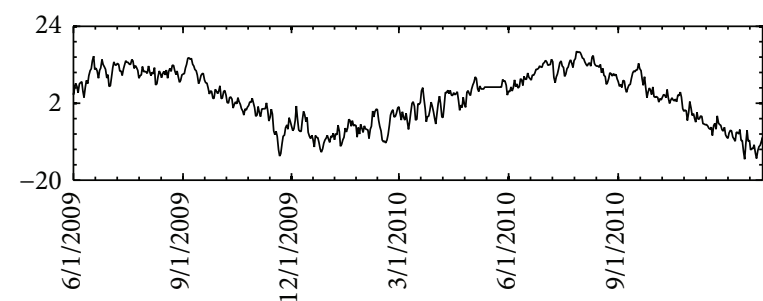

(a2)

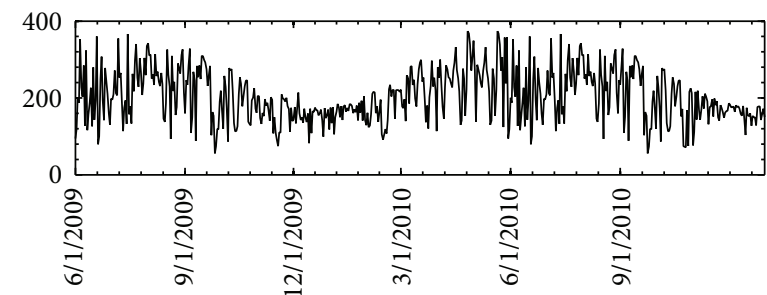

(b2)

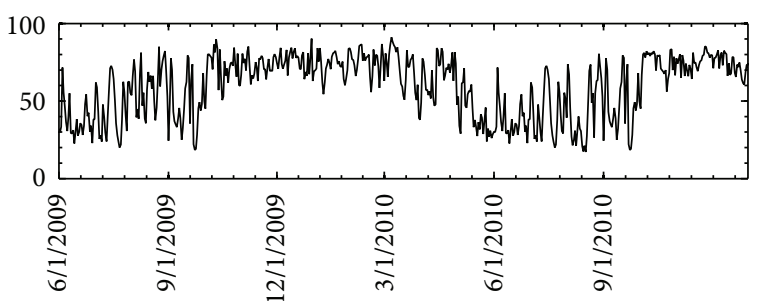

(c2)

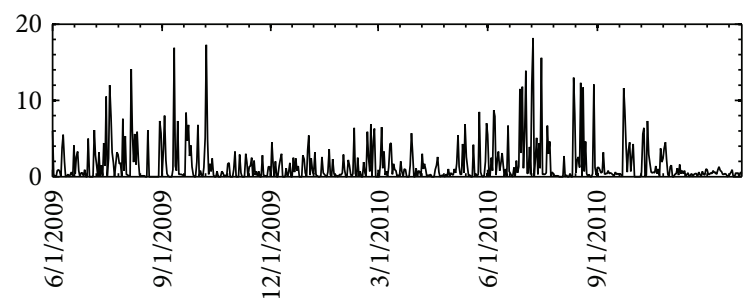

(d2)

Figure 2: The main forcing data at Madoi (left panel, from 6/1/2013 to 12/31/2014) and Zoige site (right panel, from 6/1/2009 to 12/31/2014) on the Tibetan Plateau (TP). (a1), (a2) Temperature ( $\left.{ }^{\circ} \mathrm{C}\right) ;(\mathrm{b} 1),(\mathrm{b} 2)$ incident solar $\left(\mathrm{W} \mathrm{m}^{-2}\right)$; (c1), (c2) specific humidity (\%); (d1), (d2) precipitation $\left(\mathrm{mm} \mathrm{day}^{-1}\right)$.

plates (HPF01, Wohlwend Engineering, Sennwald, Switzerland) buried 2 and $7 \mathrm{~cm}$ below the soil surface. Signals from meteorological and soil sensors were recorded at half-hourly averages with a CR23XTD data logger (Campbell Scientific, Inc.) [36].

Similar to the GS site, the raw data from ZS site from EC were processed with EddyPro flux analysis software. Spike and trend remove and coordinate rotation were also applied to the raw data as well as the coordinate rotation. Turbulent heat fluxes (the sensible heat flux and latent heat flux) were calculated with $30 \mathrm{~min}$ average and also adjusted for fluctuations in air density due to water vapor. Sporadic missing data at these two sites were replaced through linear interpolation combined with other meteorological factors.

The data used in this study spanned the period from $6 / 1 / 2013$, to $12 / 31 / 2014$, at the GS, and 6/1/2009, to $12 / 31 / 2010$, at the ZS (Figure 2). To run the CLM model, seven meteorological elements were required to force the model, including air temperature $(T)$, relativity humidity $(\mathrm{RH})$, pressure $(P)$, wind speed $(W)$, precipitation $(p)$, downward longwave radiation (DLR), and shortwave radiation (DSR). Considering the model spin-up, the first 6-month simulations (from June to December) at these two sites were discarded and regarded as the 6-month model spin-ups.

2.5. Model Setup. In this study, we use CLM4.5 in offline mode. In order to examine the capability of the new soil hydraulic parameterization scheme in CLM4.5, two numerical simulations were conducted. One is called control simulation (hereafter referred to as CTL), in which model run with the default new soil hydraulic parameterization scheme in CLM4.5; another is called sensitivity simulation (hereafter referred to as EXP), in which the new soil hydraulic properties formulas in CLM4.5 were replaced with the original ones 
TABLE 1: Values of soil parameters for different soil layers at GS site.

\begin{tabular}{|c|c|c|c|c|c|c|}
\hline Layer & Depth $z(\mathrm{~m})$ & Sand $(\%)$ & Clay $(\%)$ & Organic $\left(\mathrm{kg} \mathrm{m}^{-3}\right)$ & Canopy height $/ \mathrm{m}$ & Covered-area (alpine-meadow) \\
\hline 1 & 0.0175 & 38.64 & 26.96 & 85.00 & & \\
\hline 2 & 0.0451 & 38.64 & 26.96 & 75.12 & & \\
\hline 3 & 0.0906 & 68.60 & 14.21 & 40.14 & & \\
\hline 4 & 0.1655 & 65.41 & 21.28 & 31.37 & & \\
\hline 5 & 0.2891 & 65.41 & 21.28 & 18.14 & 0.05 & $55 \%$ \\
\hline 6 & 0.4929 & 94.03 & 3.44 & 1.92 & & \\
\hline 7 & 0.7289 & 93.42 & 2.69 & 1.18 & & \\
\hline 8 & 1.3828 & 94.17 & 3.97 & 1.10 & & \\
\hline 9 & 2.2961 & 94.17 & 3.97 & 0.00 & & \\
\hline 10 & 3.8019 & 91.52 & 4.32 & 0.00 & & \\
\hline
\end{tabular}

TABLE 2: Same as Table 1, but ZS site.

\begin{tabular}{|c|c|c|c|c|c|c|}
\hline Layer & Depth $z(\mathrm{~m})$ & Sand $(\%)$ & Clay $(\%)$ & Soil organic $\left(\mathrm{kg} \mathrm{m}^{-3}\right)$ & Canopy height $/ \mathrm{m}$ & Covered-area (alpine-meadow) \\
\hline 1 & 0.0175 & 19.25 & 2.67 & 120.40 & \multirow{10}{*}{0.20} & \multirow{10}{*}{$100 \%$} \\
\hline 2 & 0.0451 & 19.25 & 2.67 & 120.40 & & \\
\hline 3 & 0.0906 & 28.39 & 3.01 & 82.53 & & \\
\hline 4 & 0.1655 & 28.39 & 3.77 & 82.53 & & \\
\hline 5 & 0.2891 & 28.04 & 3.97 & 53.15 & & \\
\hline 6 & 0.4929 & 32.66 & 3.65 & 28.91 & & \\
\hline 7 & 0.7289 & 46.47 & 1.84 & 6.62 & & \\
\hline 8 & 1.3828 & 68.35 & 1.82 & 1.67 & & \\
\hline 9 & 2.2961 & 87.11 & 1.62 & 0.00 & & \\
\hline 10 & 3.8019 & 92.01 & 1.54 & 0.00 & & \\
\hline
\end{tabular}

in CLM4.0. The soil compositions parameters in the model at these two sites were settled based on field observations (Tables 1 and 2).

\section{Results}

3.1. Soil Liquid Water. The accuracy of soil liquid water content simulation is a significant indicator to assess the modeling capabilities of land surface models. The phase transition of soil moisture proceeds with energy absorption and release. Accurate soil liquid water content simulation has important influence on the energy redistribution between ground and atmosphere. Meanwhile, different volume partitions between ice and liquid water in the soil column could lead to different soil permeability. In addition, owing to the great huge gaps of thermal conductivity and thermal capacity between ice and liquid water, the soil liquid water content simulation could directly affect the accuracy of simulated soil temperature. In previous hydraulic properties formulas, the effect of ice on the flow of water through frozen soil is considered as a minor factor. Water in the surface layer would fail to contribute more subsurface runoff before it drains from the active layer into deeper frozen layers. And this leads to excessively dry soils in frozen soil regions [24]. In the new hydraulic properties parameterization schemes, the effect of ice on the surface layer of the hydraulic conductivity has been enlarged. The calculation of the hydraulic properties of frozen soils was modified by placing their dependence on liquid water content only. Thus, the existence and the quantity of ice would exert a significant effect on the hydraulic conductivity. The new schemes tended to reduce the dry bias existing in surface and subsurface layers with effect of decreasing the hydraulic conductivity and increasing the surface runoff. Figure 3 showed the comparison of simulated soil liquid water content between CTL and EXP simulations and also the differences between these two simulations (CTL minus EXP). Overall, new schemes in CTL tended to calculate more soil liquid water content at both of these two sites, especially in the subsurface layer. Compared to GS site, the increase at ZS site is more obvious. The high value centers of the increments at these two sites tended to occur in spring. Under the control of $f_{\text {frz }}$, the hydraulic conductivity of soil in winter is tiny until ice thawing. While thawing occurs in spring, the permeability increased rapidly. The liquid water content in the subsurface layer also increased.

The relationships between precipitation and soil liquid water content at different sites were illustrated in Figure 4 (ZS) and Figure 5 (GS), respectively. In general, the simulated peaks of soil liquid water were consistent with the rainfall. The response of the simulated soil water in a $5 \mathrm{~cm}$ layer to precipitation was more rapid than other layers, but in smaller amplitudes at these two sites. As shown in Figure 4, the model could capture the variations of measured values and the simulated peaks of soil liquid water content were well consistent with the maximum rainfall. The simulated soil liquid water content rapidly increases as rainfall occured. Compared 


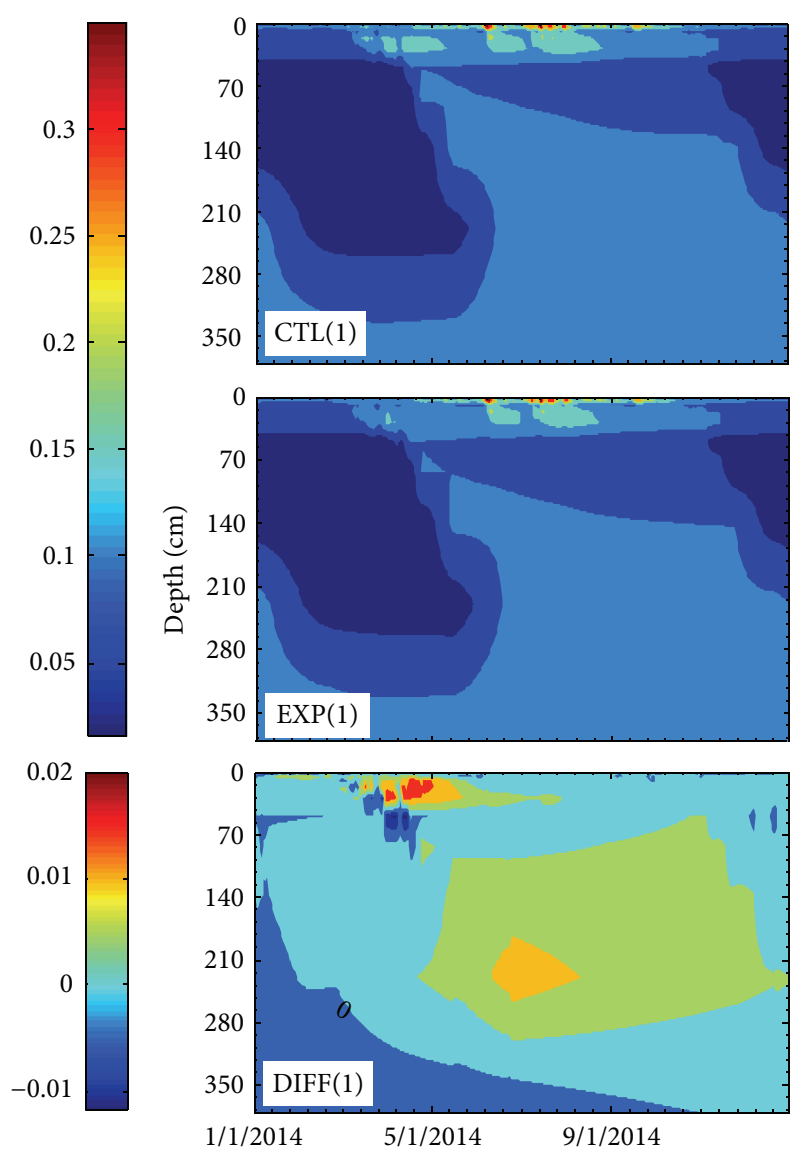

(a)

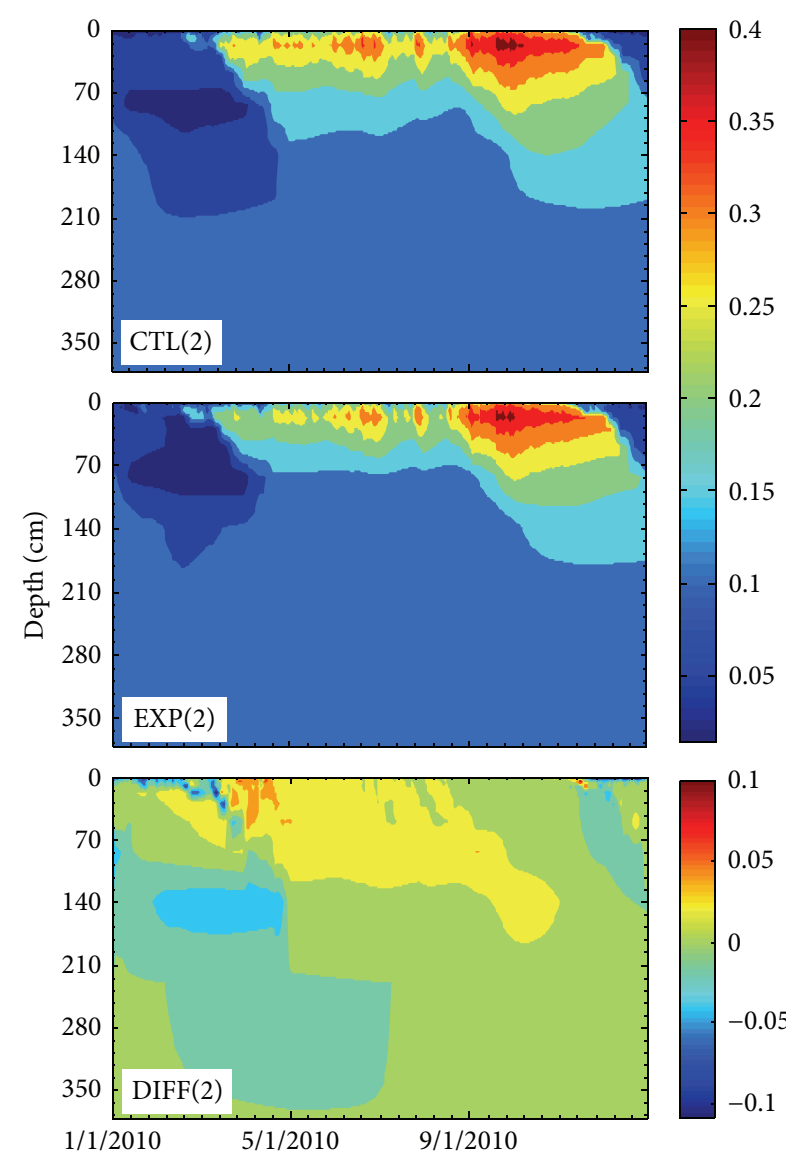

(b)

FIgURE 3: Profile of soil moisture differences (DIFF, CTL minus EXP) at different sites ((a) GS, (b) ZS).

to EXP simulation, CTL simulated wetter soil conditions in these four layers and decreased dry biases effectively (Figures 4(b)-4(e)). Simulation of CTL was captured better with the variation of observed soil liquid water content compared with EXP. The average correlation coefficient and bias of CTL (EXP) are $0.65(0.55)$ and $0.03(0.04) \mathrm{m}^{3} \mathrm{~m}^{-3}$ (Table 3).

However, as shown in Figure 5, the model tended to overestimate the soil moisture in shallow layers $(5 \mathrm{~cm}, 20 \mathrm{~cm})$ but underestimate the soil moisture in deep layers $(40 \mathrm{~cm}, 80 \mathrm{~cm})$. It is noted that both of these two simulations conducted at GS sites tended to overestimate the soil liquid content in general. The new formulars in CTL enlarged the overestimation in some time periods. New schemes in CTL conducted at ZS site increased the soil liquid water content in spring and summer and decreased the existing dry bias effectively. In contrast, modification in CTL conducted at GS played a negative role in this period. Pan et al. [38] have concluded that the existence of gravel enhanced soil drainage of the subsurface and increased the surface runoff, which could cause the gravel soil to be dryer than fine soil. Lacking consideration of the effect of gravel in the hydraulic properties schemes, in both CTL and EXP, might cause the overestimated soil water content. Owing to the wetter bias existing in EXP at GS, the new formular in CTL tended to cause larger bias compared to observation (Table 4). So, in order to get more reasonable results, refining
TABLE 3: Statistical results of simulated soil liquid water content from CTL and EXP at ZS site.

\begin{tabular}{lccccc}
\hline & $5 \mathrm{~cm}$ & $20 \mathrm{~cm}$ & $40 \mathrm{~cm}$ & $80 \mathrm{~cm}$ & Average \\
\hline$r$ & & & & & \\
CTL & 0.73 & 0.74 & 0.71 & 0.40 & 0.65 \\
EXP & 0.64 & 0.68 & 0.63 & 0.26 & 0.55 \\
\hline Bias $\left(\mathrm{m}^{3} \mathrm{~m}^{-3}\right)$ & & & & & \\
CTL & -0.05 & 0.04 & -0.02 & -0.02 & 0.03 \\
EXP & -0.07 & 0.02 & -0.04 & -0.04 & 0.04 \\
\hline
\end{tabular}

improvements of the hydraulic conductivity and the thermal conductivity parameterized schemes are needed.

3.2. Soil Temperature. The soil temperature simulation depends on the accuracy of simulated soil thermal conductivity and heat capacity. The thermal conductivity and the heat capacity of ice are $2.2 \mathrm{~W} \mathrm{~m}^{-1} \mathrm{~K}^{-1}$ and $1.9 \mathrm{MJ} \mathrm{m}^{-3} \mathrm{~K}^{-1}$, while those of the liquid water are $0.56 \mathrm{~W} \mathrm{~m}^{-1} \mathrm{~K}^{-1}$ and 4.2 $\mathrm{MJ} \mathrm{m}^{-3} \mathrm{~K}^{-1}$, respectively. Based on these great gaps, the soil moisture simulation could influence the simulated soil temperature directly. Figure 6 showed the comparison of simulated soil temperature from CTL and EXP simulation and also the differences between these two simulations 


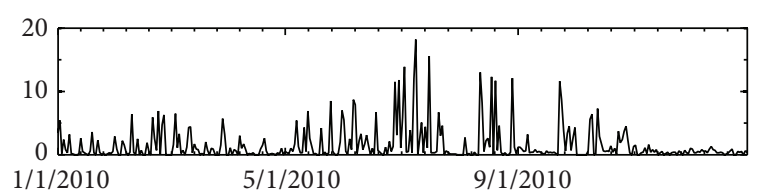

(a)

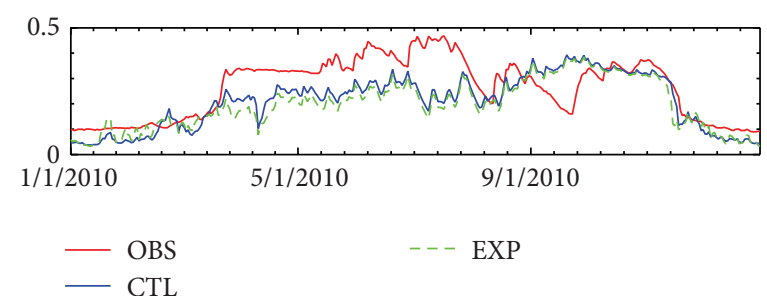

(b)

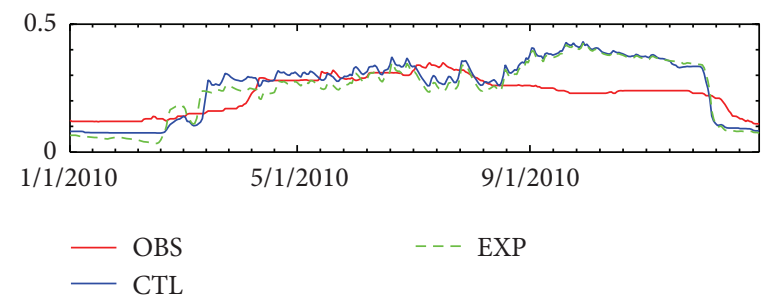

(c)

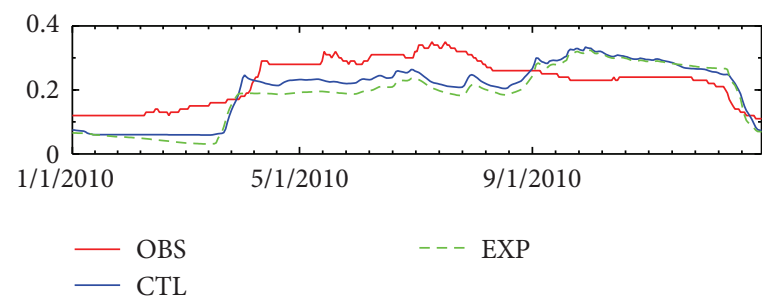

(d)

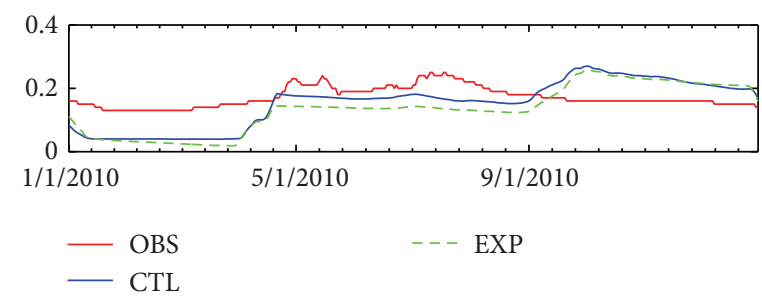

(e)

FIGURE 4: Daily average precipitation $\left(\mathrm{mm} \mathrm{day}^{-1}\right)$ (a) and soil moisture $\left(\mathrm{m}^{3} \mathrm{~m}^{-3}\right)$ at (b) $5 \mathrm{~cm}$, (c) $20 \mathrm{~cm}$, (d) $40 \mathrm{~cm}$, and (e) $80 \mathrm{~cm}$ at $\mathrm{ZS}$ site.

(CTL minus EXP). Owing to wetter soil conditions in CTL conducted at the two sites, the relatively larger heat capacity of liquid water in the soil made the simulated soil warmer than that from EXP simulation. Temperature difference between CTL and EXP was more obvious at ZS site.

Comparisons of simulated soil temperature with observations at certain depths at different sites were shown in Figure 7 (ZS) and Figure 8 (GS), respectively. The simulated soil temperatures in CTL and EXP are generally close to

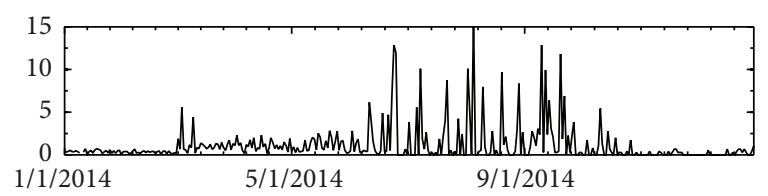

(a)

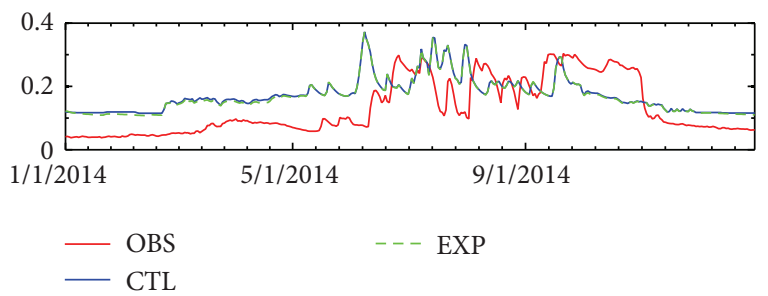

(b)

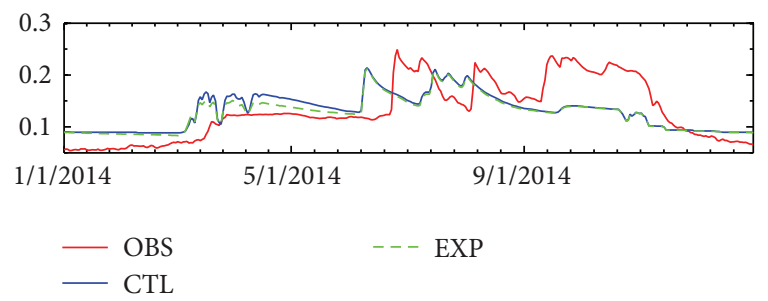

(c)

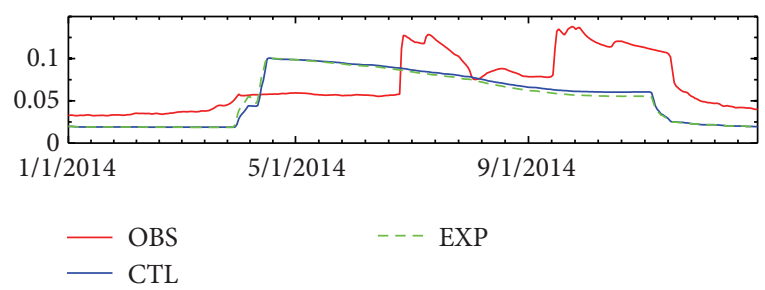

(d)

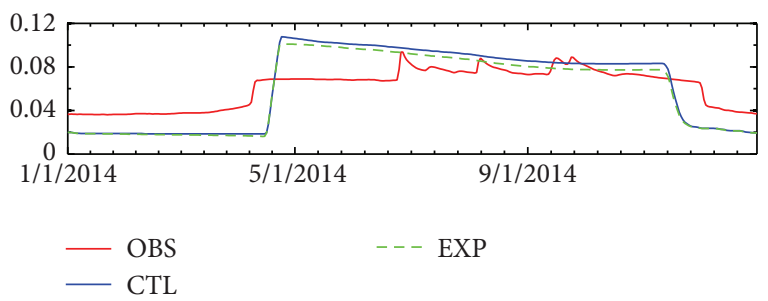

(e)

FIgURE 5: Same as Figure 4 but at GS site.

the measurements in shallow layers and obviously underestimated in deep layers (Tables 5 and 6). Also, the amplitudes of simulated soil temperature at $5 \mathrm{~cm}$ depth are smaller compared to the observations.

3.2.1. Freeze/Thaw Cycle of Soil. Four freeze/thaw stages were identified: the completely frozen stage (the maximum daily soil temperature below $0^{\circ} \mathrm{C}$ ); the thawing stage (the soil column profile is experiencing thawing process); the completely thawed stage (the minimum daily soil temperature stay above $0^{\circ} \mathrm{C}$ ); and the freezing stage (the soil column is experiencing freezing process). Meanwhile, ground diurnal freeze/thaw cycles were judged to have occurred when the 


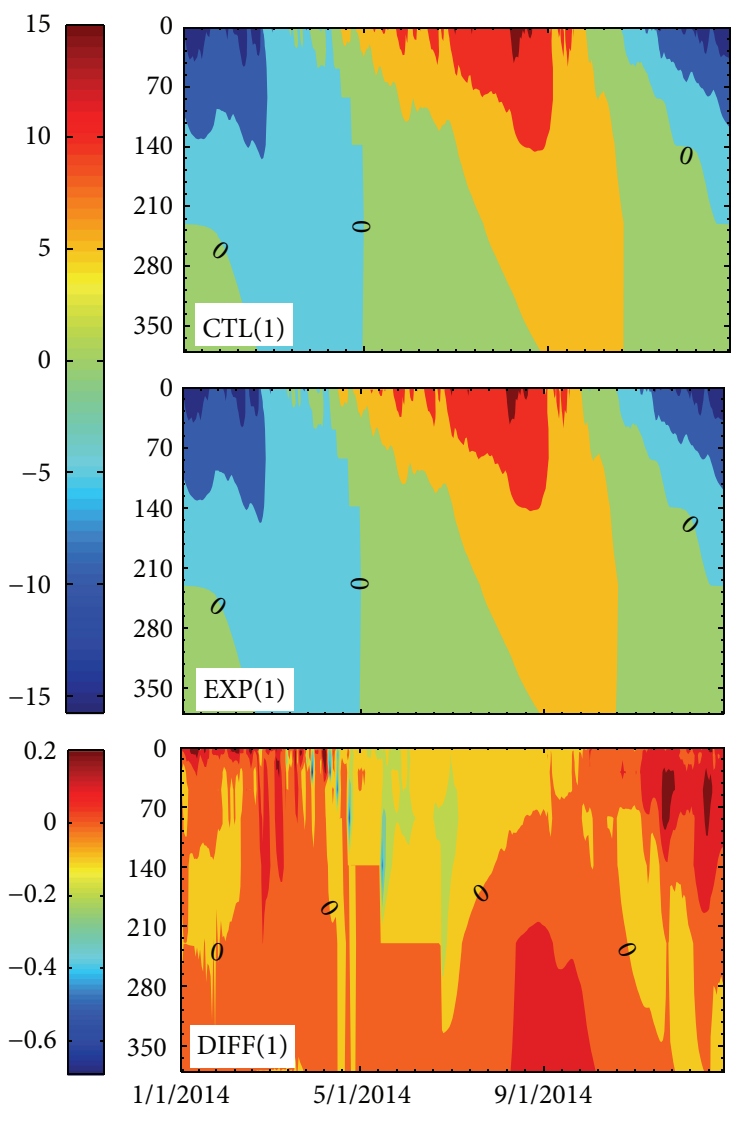

(a)

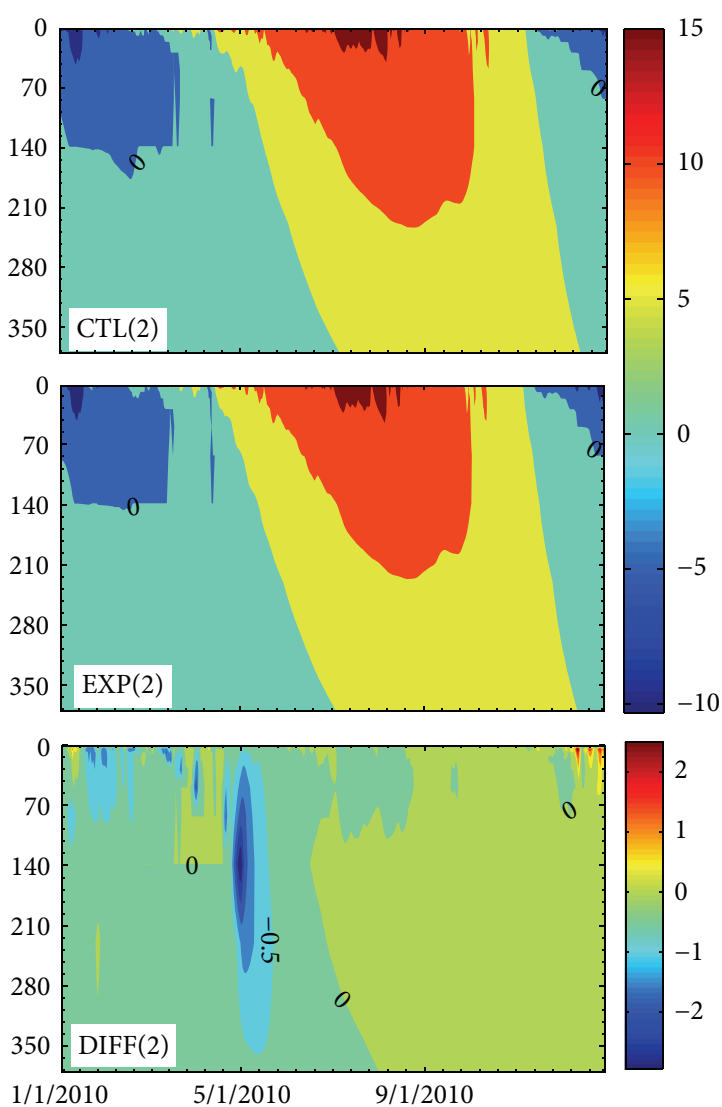

(b)

FIgURE 6: Profile of soil temperature differences (CTL minus EXP) at (a) GS and (b) ZS site.

TABLE 4: Same as Table 3 but at GS site.

\begin{tabular}{lccccc}
\hline & $5 \mathrm{~cm}$ & $20 \mathrm{~cm}$ & $40 \mathrm{~cm}$ & $80 \mathrm{~cm}$ & Average \\
\hline$r$ & & & & & \\
CTL & 0.49 & 0.56 & 0.47 & 0.86 & 0.60 \\
EXP & 0.50 & 0.60 & 0.43 & 0.86 & 0.60 \\
\hline Bias $\left(\mathrm{m}^{3} \mathrm{~m}^{-3}\right)$ & & & & & \\
CTL & 0.04 & -0.01 & -0.02 & 0.00 & 0.02 \\
EXP & 0.04 & -0.04 & -0.02 & -0.01 & 0.03 \\
\hline
\end{tabular}

TABLE 5: Statistical results of simulated soil temperature from CTL and EXP at ZS site.

\begin{tabular}{cccccc}
\hline & $5 \mathrm{~cm}$ & $20 \mathrm{~cm}$ & $40 \mathrm{~cm}$ & $80 \mathrm{~cm}$ & Average \\
\hline$r$ & & & & & \\
CTL & 0.94 & 0.98 & 0.98 & 0.99 & 0.97 \\
EXP & 0.94 & 0.98 & 0.98 & 0.98 & 0.97 \\
\hline Bias $\left({ }^{\circ} \mathrm{C}\right)$ & & & & & \\
CTL & 0.79 & -0.13 & -1.17 & -0.27 & 0.59 \\
EXP & 0.84 & 0.01 & -1.01 & -0.12 & 0.50 \\
\hline
\end{tabular}

daily maximum soil temperature was above $0^{\circ} \mathrm{C}$ and the minimum soil temperature was subzero. In order to avoid the potential impact of random weather processes on the
TABLE 6: Same as Table 5 but at GS site.

\begin{tabular}{cccccc}
\hline & $5 \mathrm{~cm}$ & $20 \mathrm{~cm}$ & $40 \mathrm{~cm}$ & $80 \mathrm{~cm}$ & Average \\
\hline$r$ & & & & & \\
CTL & 0.95 & 0.96 & 0.97 & 0.98 & 0.97 \\
EXP & 0.95 & 0.96 & 0.97 & 0.98 & 0.97 \\
\hline Bias $\left({ }^{\circ} \mathrm{C}\right)$ & & & & & \\
CTL & 1.30 & 1.58 & 1.39 & 0.32 & 1.15 \\
EXP & 1.27 & 1.57 & 1.38 & 0.32 & 1.14 \\
\hline
\end{tabular}

judgement, the occurrence of three consecutive days meeting a chosen set of criteria was used as an indicator of the transition, and the first day was recorded as the starting date of the next freeze/thaw stage [39]. Based on this assumption, four freeze/thaw stages at depth of $10 \mathrm{~cm}$ were identified at the two sites (Figure 9 and Table 7). Figures 10 and 11 presented the observed and simulated diurnal variations of soil temperatures at $10 \mathrm{~cm}$ under the surface on each stage at these two sites. One month in each stage was selected as a representative.

Based on the observations at ZS (GS), the soil was completely frozen on $1 / 1 / 2010$ to $3 / 19 / 2010$ (1/1/2014 to $3 / 27 / 2014$ ), thawing on $3 / 20$ to $4 / 3(3 / 28$ to $5 / 2)$ until completely thawed on $4 / 4$ to $11 / 11(5 / 3$ to $10 / 20)$, and refreezing on $11 / 12(10 / 21)$. Compared to EXP, the CTL performed better at ZS site for 


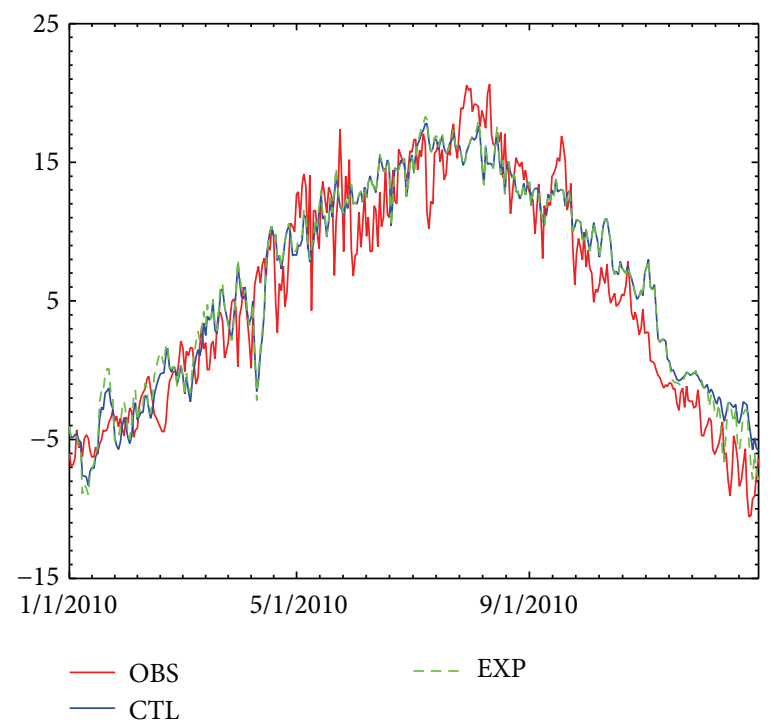

(a)

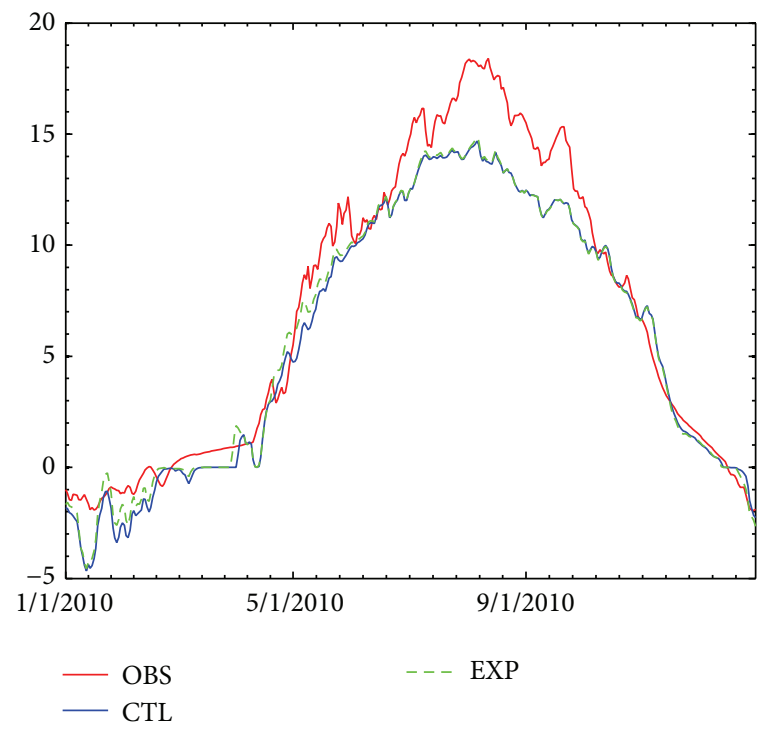

(c)

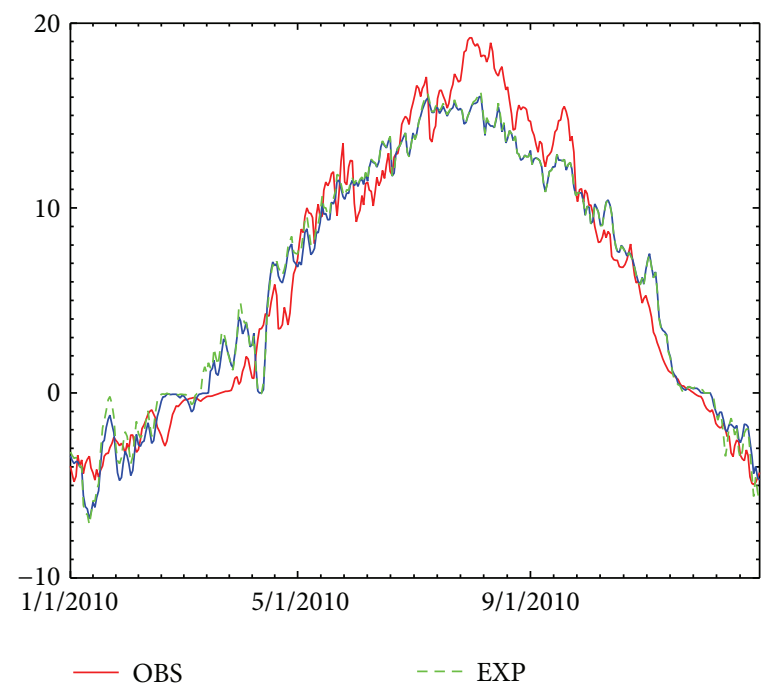

(b)

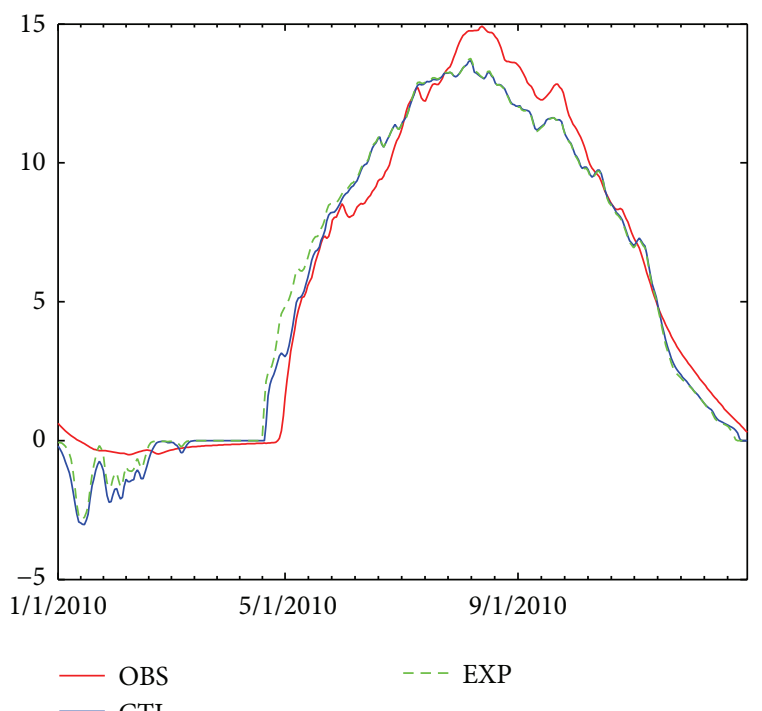

(d)

Figure 7: Daily average soil temperature $\left({ }^{\circ} \mathrm{C}\right.$ ) at (a) $5 \mathrm{~cm}$, (b) $20 \mathrm{~cm}$, (c) $40 \mathrm{~cm}$, and (d) $80 \mathrm{~cm}$ at ZS site.

simulating the starting dates of four stages, especially on the thawing stages. Because the hydraulic conductivity was calculated based on liquid water content in the CTL, the movement of water through frozen soil decreased greatly while porosities in the surface layer were filled with ice. As surface ice melted at progressively deeper depths, water infiltrates further into the deeper layer. However, in the old scheme in the EXP, the relatively warm water could infiltrate in the deeper frozen layer while the surface was icy, thus making the deeper layer begin to melt immediately. This led to the advanced melting date. In addition, due to the wetter surface during simulation at ZS site, an increased heat capacity in the surface ground induced the decrescent diurnal range of soil temperature during the freezing-thawing process and the simulated surface soil temperature agreed better with the observed in the completely frozen and thawed stages than that in the freezing-thawing periods. For the simulations of starting dates of the four soil freeze-thaw stages at GS site, the new soil hydraulic properties scheme did not show prominent advantages due to its undistinguished performance of soil temperature in simulations on the surface. Both of these two schemes tended to simulate longer thawing/freezing stage but shorter thawed/frozen stage compared to the observation. The wetter surface conditions were simulated at GS site releasing (absorbing) more energy in the freezing (thawing) stage, which expanded the daily amplitudes of surface soil temperatures compared to the observations (Figures 11(b) and $11(\mathrm{~d})$ ). 


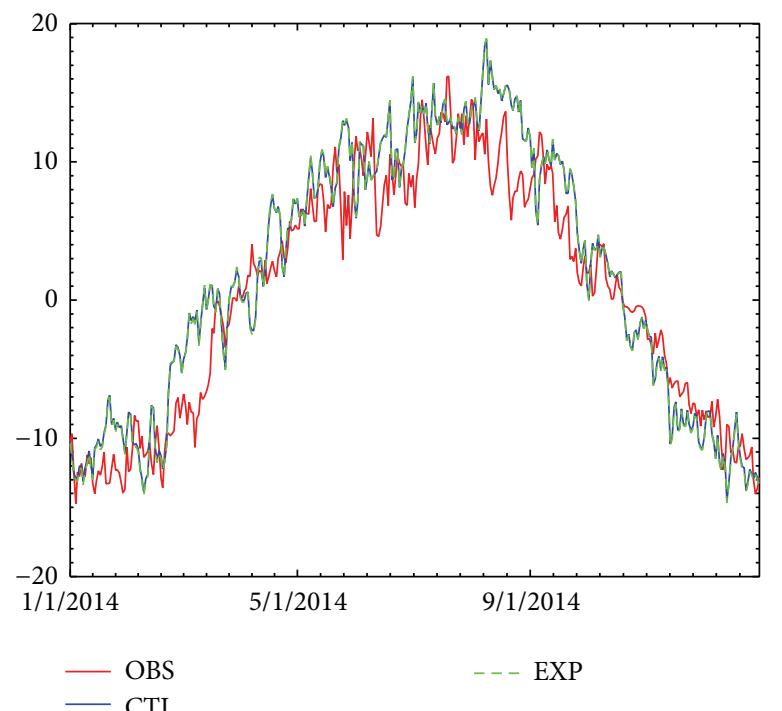

(a)

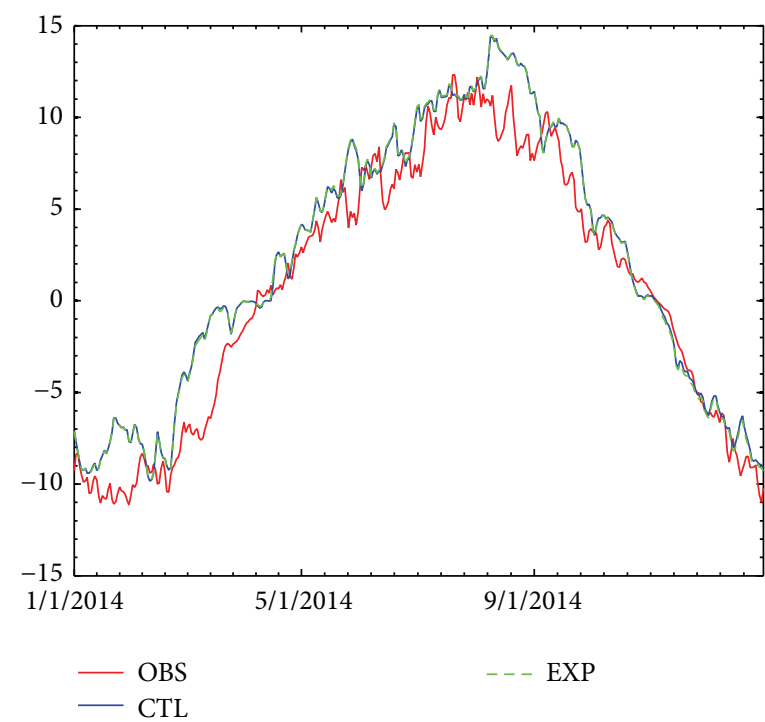

(c)

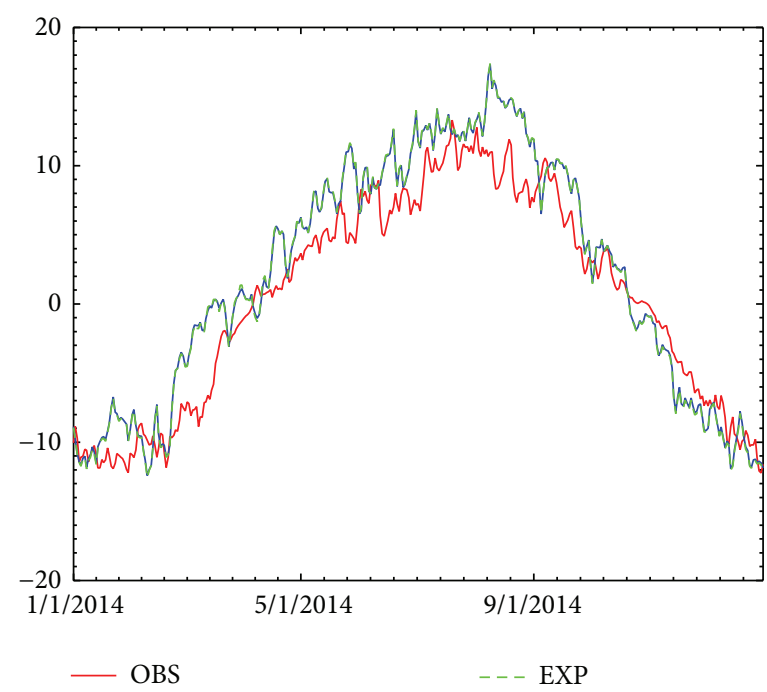

(b)

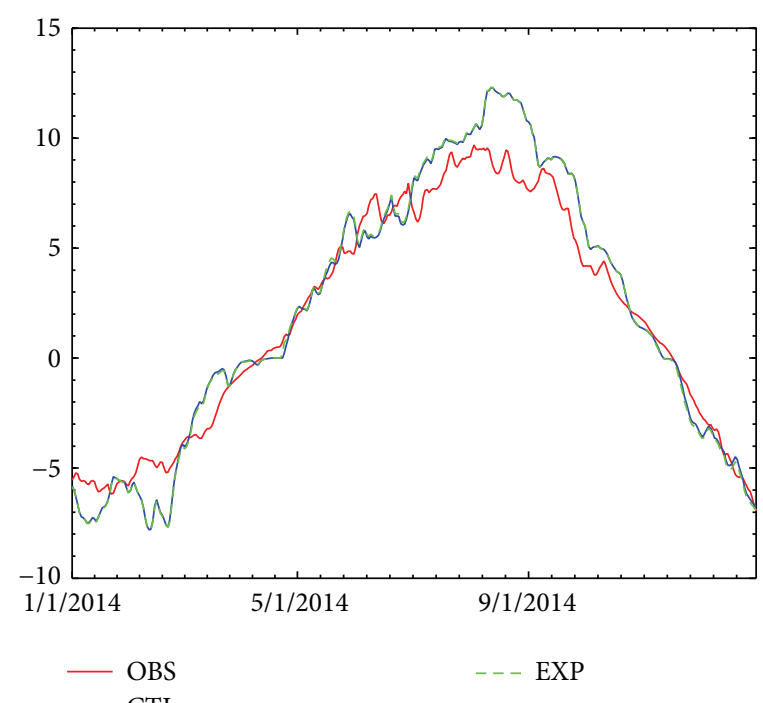

(d)

FIGURE 8: Daily average soil temperature $\left({ }^{\circ} \mathrm{C}\right.$ ) at (a) $5 \mathrm{~cm}$, (b) $20 \mathrm{~cm},(\mathrm{c}) 40 \mathrm{~cm}$, and (d) $80 \mathrm{~cm}$ at GS site.

3.3. Surface Energy. CLM follows the principle of surface energy balance:

$$
R_{n}=H+\mathrm{LE}+G,
$$

where radiation flux $\left(R_{n}\right)$ is the difference between the surface absorbed shortwave radiation and the surface effective radiation. Sensible heat flux $(H)$ is the energy flux transferred due to turbulent motion. Latent heat flux (LE) is the energy flux transferred due to the phase change of water vapor. Surface soil heat flux $(G)$ is the energy transferred between soil and the atmosphere through the surface ground. When the atmosphere transmits energy to the soil, $G$ is positive, but when the soil transmits energy to the atmosphere, it is negative.

Because energy components data at GS site were missing for a long time during the studied period, we have not analyzed that site. We also conducted the offline simulation using CLM4.0 with the same model parameter definitions used in CTL during 2010 at ZS site helping to make the assessment more completely. We defined the runs of CLM4.0 as EXP1, to distinguish them from the EXP. Sensitivity analysis of EXP has also been carried out. Figure 12 illustrated the difference between the CTL and sensitivity experiments (CTL minus EXP1, CTL minus EXP) on 1/1/2010-12/31/2010. As shown in Figure 12, compared to CLM4.0, CLM4.5 increased simulation of latent heat flux and decreased the sensible heat flux. Guo et al. [39] have expounded the negative correlation between sensible heat flux and latent heat flux and the positive correlation between the diurnal range of latent heat flux and liquid water content. The prominent reduction in $H$ and the increasing in LE simulations indicated the wetter soil conditions simulated in CLM4.5 compared 
TABLE 7: Four freeze-thaw stages determined the daily maximum and minimum soil temperatures at $10 \mathrm{~cm}$ under the surface (month-days).

\begin{tabular}{|c|c|c|c|c|}
\hline & Frozen & Thawing & Thawed & Freezing \\
\hline \multicolumn{5}{|l|}{ GS } \\
\hline OBS & $\begin{array}{c}1 / 1 /-3 / 27 / 2014 \\
\text { (86 days) }\end{array}$ & $\begin{array}{c}3 / 28 /-5 / 2 / 2014 \\
\text { (36 days) }\end{array}$ & $\begin{array}{c}5 / 3 /-10 / 20 / 2014 \\
\text { (171 days) }\end{array}$ & $\begin{array}{c}10 / 21 /-12 / 31 / 2014 \\
(72 \text { days })\end{array}$ \\
\hline CTL & $\begin{array}{c}\text { 1/1-3/4/2014 } \\
\text { (63 days) }\end{array}$ & $\begin{array}{c}3 / 5 /-4 / 29 / 2014 \\
\text { (56 days) }\end{array}$ & $\begin{array}{c}4 / 30 /-9 / 26 / 2014 \\
\text { (150 days) }\end{array}$ & $\begin{array}{c}9 / 27 /-12 / 31 / 2014 \\
\text { (96 days) }\end{array}$ \\
\hline EXP & $\begin{array}{c}\text { 1/1-3/4/2014 } \\
\text { (63 days) }\end{array}$ & $\begin{array}{c}3 / 5 /-4 / 29 / 2014 \\
\text { (56 days) }\end{array}$ & $\begin{array}{c}4 / 30 /-9 / 26 / 2014 \\
(150 \text { days })\end{array}$ & $\begin{array}{c}9 / 27 /-12 / 31 / 2014 \\
\text { (96 days) }\end{array}$ \\
\hline \multicolumn{5}{|l|}{ ZS } \\
\hline OBS & $\begin{array}{c}\text { 1/1/-3/19/2010 } \\
\text { (78 days) }\end{array}$ & $\begin{array}{c}3 / 20 /-4 / 3 / 2010 \\
(15 \text { days })\end{array}$ & $\begin{array}{c}\text { 4/4/-11/11/2010 } \\
(222 \text { days })\end{array}$ & $\begin{array}{c}11 / 12 /-12 / 31 / 2010 \\
\text { (50 days) }\end{array}$ \\
\hline CTL & $\begin{array}{c}\text { 1/1/-3/11/2010 } \\
\text { (70 days) }\end{array}$ & $\begin{array}{c}\text { 3/12/-3/28/2010 } \\
\text { (17 days })\end{array}$ & $\begin{array}{c}3 / 29 /-11 / 12 / 2010 \\
\text { (229 days) }\end{array}$ & $\begin{array}{c}11 / 13 /-12 / 31 / 2010 \\
\text { (49 days) }\end{array}$ \\
\hline EXP & $\begin{array}{c}\text { 1/1/-2/17/2010 } \\
\text { (48 days })\end{array}$ & $\begin{array}{c}2 / 18 /-4 / 13 / 2010 \\
(55 \text { days })\end{array}$ & $\begin{array}{c}\text { 4/14/-11/11/2010 } \\
\text { (212 days) }\end{array}$ & $\begin{array}{c}11 / 12 /-12 / 31 / 2010 \\
\text { (50 days) }\end{array}$ \\
\hline
\end{tabular}

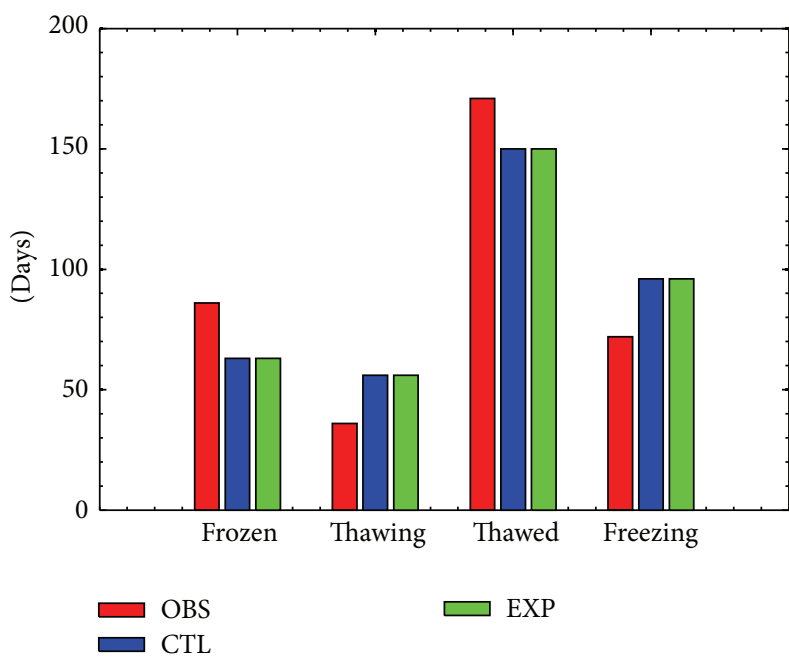

(a)

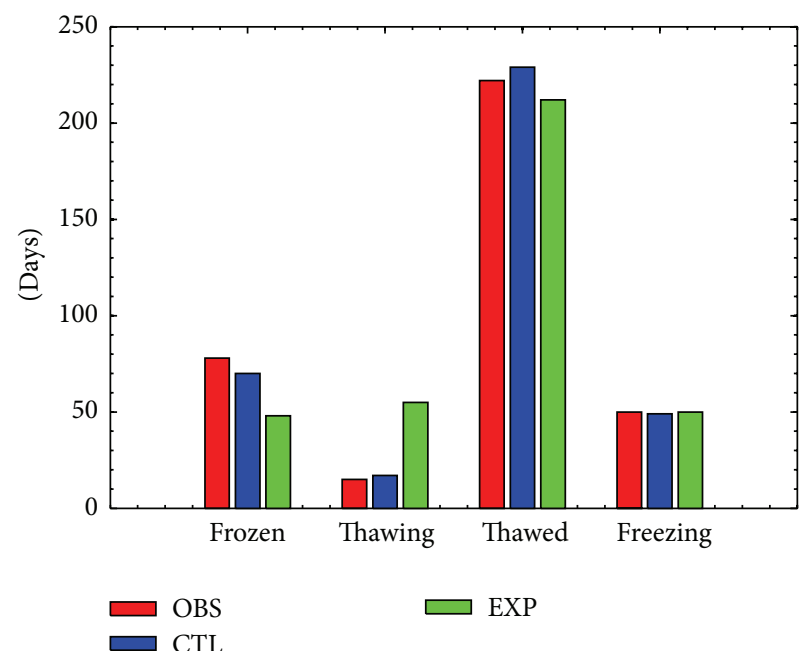

(b)

FIGURE 9: Observed and simulated days in each freezing and thawing stage at different sites. (a) is for the GS site. (b) is for the ZS site.

to CLM4.0. Actually, to simulate the environment more realistically, CLM4.5 computed the surface fluxes separately for snow-covered and snow-free fractions of a grid cell, rather than the uniform snow cover assumption adopted in previous versions [25]. Based on the snow water equivalent rather than the mean snow depth and snow density, CLM4.5 tends to reduce the overestimate SCF in previous versions. The decreased SCF and the direct exposure of snow-free fraction to the atmosphere made the surface ground experience more heat loss during autumn and greater heat gain in spring. The difference of $R_{n}$ and $G$ between CTL and EXP also experienced the variations from negative to positive (Figures 12(c) and $12(\mathrm{~d}))$.

Furthermore, advanced thawing date simulated in EXP made the surface wetter compared to CTL, thus leading to the higher LE and lower $H$ during the frozen stage (Figures 12(a) and 12(b)). As the surface soil is thawing in advance in the EXP, the model tends to simulate the underestimated snow cover and the albedo, thus higher $R_{n}$ and $G$ values (Table 8). Figures $12(\mathrm{c})$ and $12(\mathrm{~d})$ also clearly show the negative difference values between the CTL and the EXP on the frozen stage.

As shown in Figure 13, the simulated daily mean energy fluxes were compared with direct measurements. The relatively wetter surface soil in CLM4.5 enlarged the latent heat flux and decreased the sensible heat flux, which agreed better with measured results during our study period as shown in Figures 13(a) and 13(b). Profiting from new parameterization schemes in CLM4.5, the CTL tended to capture the observed daily energy variations more reasonably, except for the slightly underestimated $H$. Also, it is apparent that CLM4.5 yielded smaller biases clearly, but with slightly lower pertinences with measured results. Frequent surface freeze-thaw cycles could affect the energy distribution [10]. 
TABLE 8: Statistical results of daily mean energy flux components between simulations and observation at ZS site.

\begin{tabular}{lcccc}
\hline & $H$ & LE & $R_{n}$ & $G$ \\
\hline$r$ & & & & \\
CTL & 0.23 & 0.78 & 0.73 & 0.47 \\
EXP & 0.29 & 0.76 & 0.72 & 0.44 \\
EXP1 & 0.22 & 0.82 & 0.73 & 0.48 \\
\hline Bias $\left(W^{-3}\right)$ & & & & \\
CTL & 10.40 & -0.07 & 0.27 & 0.92 \\
EXP & 8.80 & -0.97 & 0.40 & 0.54 \\
EXP1 & 23.25 & -13.83 & 2.32 & 0.87 \\
\hline
\end{tabular}

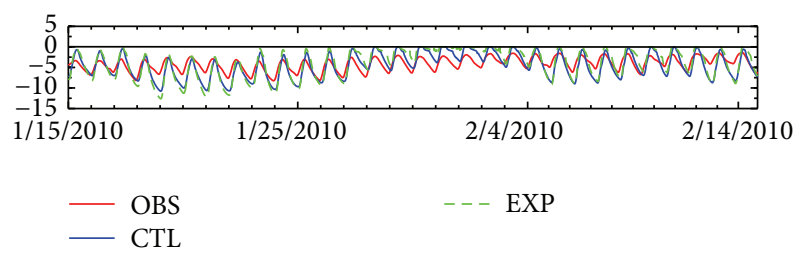

(a)

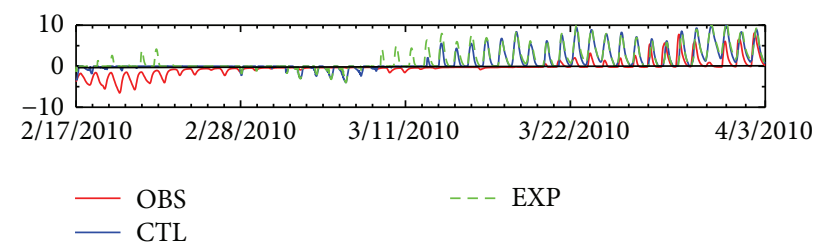

(b)

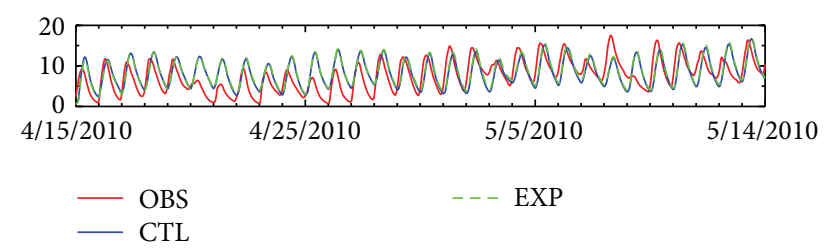

(c)

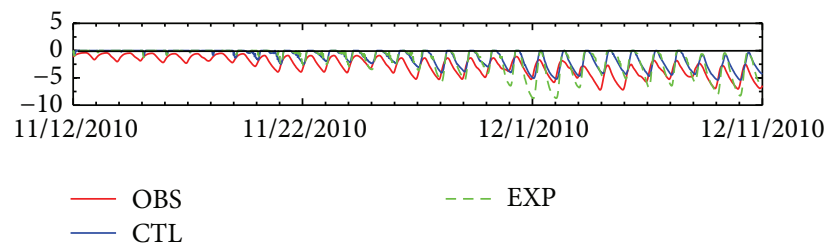

(d)

Figure 10: Diurnal variations of soil temperature in the $10 \mathrm{~cm}$ soil layer in four freeze-thaw stages in the ZS site. (a) Completely frozen, (b) thawing, (c) completely thawed, and (d) freezing.

Majorizations of numerical description of the hydraulic and thermal properties in CLM during freeze/thaw cycle are still needed to make the energy flux simulation more reasonable.

\section{Conclusions}

This study conducted offline numerical simulations at two typical sites on the TP. The simulation ability of the newly released land surface model CLM4.5 was examined and

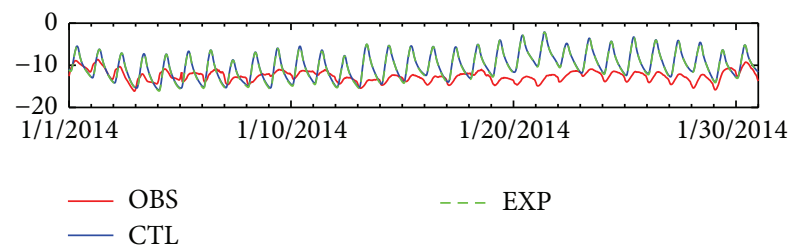

(a)

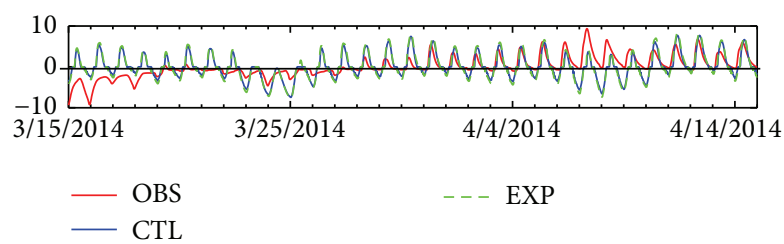

(b)

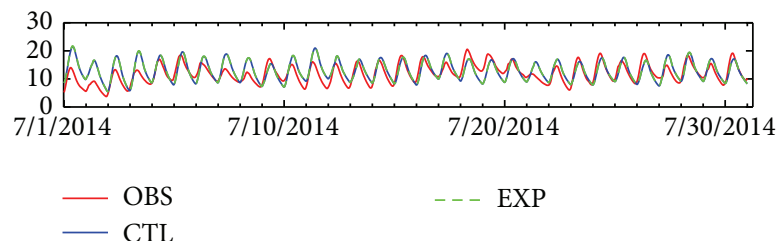

(c)

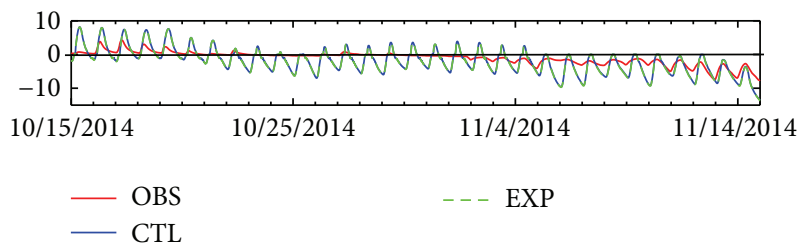

(d)

FIGURE 11: Same as Figure 10 but at GS site.

the improvements of the new hydraulic properties scheme, which has direct effects on the simulation of freeze-thaw cycles and the hydraulic-thermal properties of seasonal frozen soil via the relative sensitivity analysis, were verified. The conclusions are as follows:

(1) The model can capture the variations of measured soil liquid water contents and the simulated peaks well consistent with the maximum rainfall. The new hydraulic properties scheme can effectively reduce the dry bias existing in surface soil at ZS. However, lacking consideration of the gravel effect made the modification not significant at GS site. The existence of gravel could cause the gravel soil to be dryer than fine soil. Failure to dispose the gravel in the model formulas made the simulated soil liquid water content overestimated compared to the observation. In contrast, modification in CTL conducted at GS site played a negative role.

(2) The wetter surface condition in CLM4.5 also led to the warmer surface soil temperature because of the greater heat capacity of liquid water. The accuracy of soil temperature simulation is closely related to 


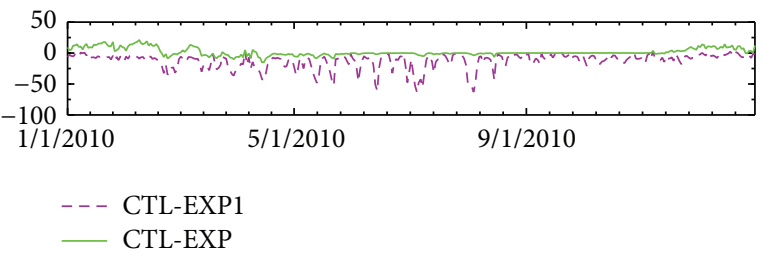

(a)

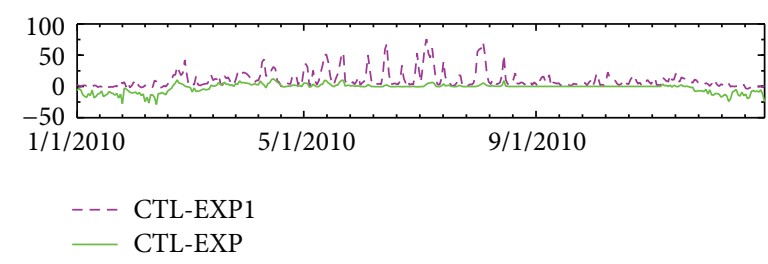

(b)

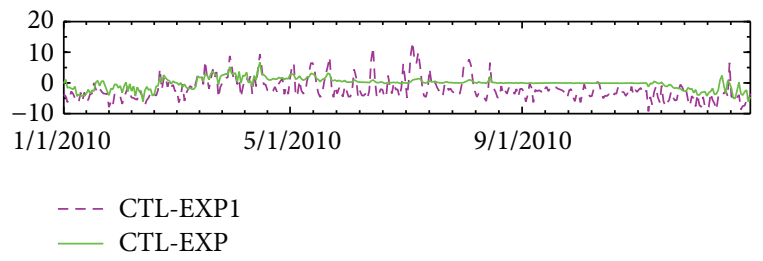

(c)

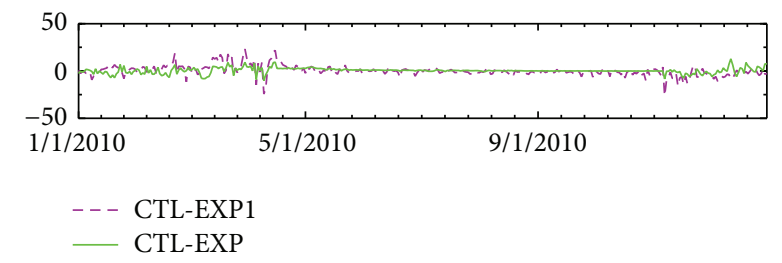

(d)

FIGURE 12: Differences of daily mean energy flux $\left(\mathrm{W} \mathrm{m}^{-2}\right.$ ) (a) $H$, (b) LE, (c) $R_{n}$, and (d) $G$ between the CTL and EXP simulations at ZS site.

the simulated soil moisture. Temperature difference between CTL and EXP is more obvious at ZS. The CTL performed better at ZS for simulating the starting dates of four stages compared to EXP, especially on the thawing stages. Under the influences of the ice impedance function and the new hydraulic properties schemes in CTL, the movement of water through frozen soil has been decreased greatly. As surface ice melts at progressively deeper depths, water infiltrates further into the deeper layer. This delayed the melting date effectively. In addition, the increased heat capacity in the surface ground at ZS also induced the decreased diurnal range of soil temperature during the freezing-thawing process which agreed better with the observation. However, at GS, CTL did not show prominent advantages due to its undistinguished performance of soil liquid water content simulations on the surface.

(3) CLM4.5 computed the surface fluxes separately for snow-covered and snow-free fractions of a grid cell, rather than the uniform snow cover assumption

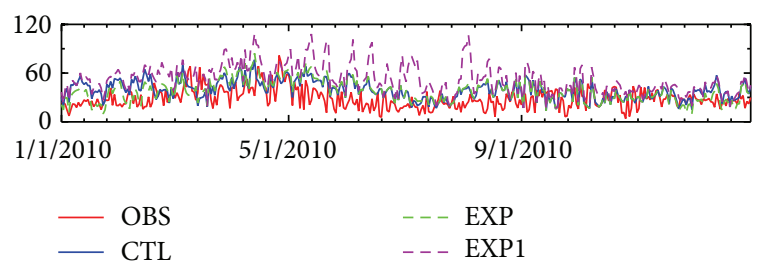

(a)

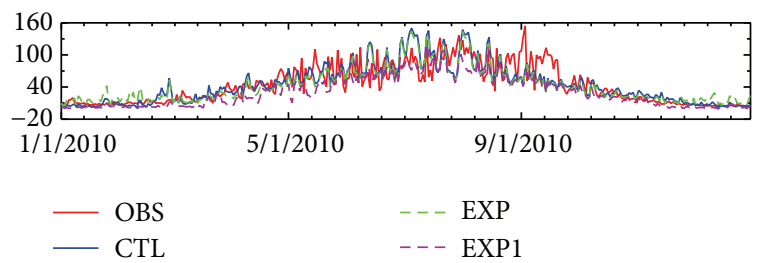

(b)

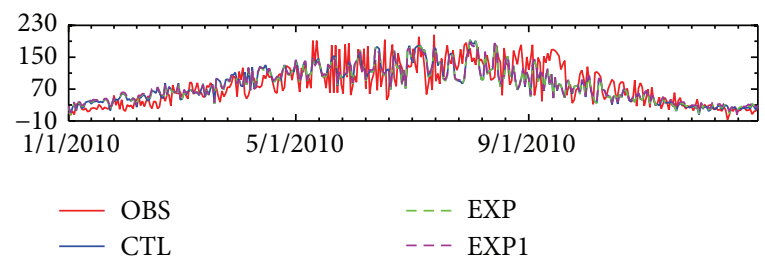

(c)

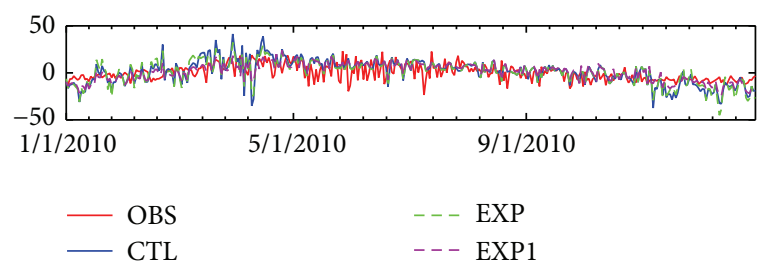

(d)

FIGURE 13: Same as Figure 12 but daily mean variations of energy flux between observation and simulations.

adopted in previous versions. Decreased snow covers fraction resulted in the lower albedo. This reduction in surface albedo tended to increase net surface radiation in CLM4.5 compared to previous versions. Furthermore, the improvement in freeze/thaw starting dates simulations also led to the more reasonable turbulent fluxes simulations.

In summary, CLM4.5 could capture the hydrologicalthermal interactions of seasonal frozen soil on the TP. The land surface model could simulate a more realistic land surface climate and then positively impact on the climate prediction while coupled with the regional climate models. However, the optimization concerning the numerical description of the hydraulic and thermal properties during freeze/thaw cycle based on the endemic soil texture on the $\mathrm{TP}$ is still needed in future study.

\section{Competing Interests}

The authors declare that they have no competing interests. 


\section{Acknowledgments}

This work was supported by the National Natural Science Foundation of China, Grants 41375077, 41130961, 91537104, and 41405088 . The observation data were provided by the Zoige Plateau Wetlands Ecosystem Research Station and the GS Grassland Station under sponsorship of the National Science Foundation. The authors acknowledge computing resources and time from the Supercomputing Center, Big Data Center of Cold and Arid Region Environment and Engineering Research Institute, Chinese Academy of Sciences.

\section{References}

[1] A. Duan, Y. Liu, and G. Wu, "Heating status of the Tibetan Plateau from April to June and rainfall and atmospheric circulation anomaly over East Asia in midsummer," Science in China Series D: Earth Sciences, vol. 48, no. 2, pp. 250-257, 2005.

[2] Z. Gao, N. Chae, J. Kim, J. Hong, T. Choi, and H. Lee, "Modeling of surface energy partitioning, surface temperature, and soil wetness in the Tibetan prairie using the Simple Biosphere Model 2 (SiB2)," Journal of Geophysical Research D: Atmospheres, vol. 109, no. 6, Article ID D06102, pp. 439-447, 2004.

[3] K. Yang, T. Koike, B. Ye, and L. Bastidas, "Inverse analysis of the role of soil vertical heterogeneity in controlling surface soil state and energy partition," Journal of Geophysical Research Atmospheres, vol. 110, no. 8, pp. 1-15, 2005.

[4] X. Chen, M. Yang, G. Wan, X. Wang, X. Luo, and X. Liang, "Simulation studies of CLM3 and SHAW at NMQ station on the central tibetan plateau," Journal of Glaciology \& Geocryology, vol. 35, no. 2, pp. 291-300, 2013.

[5] M. Song, Y. Ma, Y. Zhang, W. Ma, and S. Luo, "An off-line simulation of land surface processes over the northern Tibetan Plateau," Science in Cold and Arid Regions, vol. 3, pp. 236-246, 2014.

[6] S. Luo, S. Lü, and Y. Zhang, "Development and validation of the frozen soil parameterization scheme in Common Land Model," Cold Regions Science \& Technology, vol. 55, no. 1, pp. 130-140, 2009.

[7] S.-Q. Luo, S.-H. Lü, Y. Zhang et al., "Soil thermal conductivity parameterization establishment and application in numerical model of central Tibetan Plateau," Chinese Journal of Geophysics, vol. 52, no. 4, pp. 919-928, 2009.

[8] G. Bonan, "A land surface model (LSM version 1.0) for ecological, hydrological, and atmospheric studies: technical description and user's guide," Tech. Rep. NCAR.TN-417+STR, National Center for Atmospheric Research Tech Note, Boulder, Colo, USA, 1996.

[9] D. M. Lawrence, A. G. Slater, V. E. Romanovsky, and D. J. Nicolsky, "Sensitivity of a model projection of near-surface permafrost degradation to soil column depth and representation of soil organic matter," Journal of Geophysical Research: Earth Surface, vol. 113, no. 2, pp. 250-258, 2008.

[10] B. Chen, S. Luo, S. Lü, Y. Zhang, and D. Ma, "Effects of the soil freeze-thaw process on the regional climate of the QinghaiTibet Plateau," Climate Research, vol. 59, no. 3, pp. 243-257, 2014.

[11] S. Luo, S. Lu, Y. Zhang et al., "Simulation analysis on land surface process of BJ site of central Tibetan using CoLM," Plateau Meteorology, vol. 27, no. 2, pp. 259-271, 2008.
[12] Y. Xin, B. Wu, L. Bian, G. Liu, L. Zhang, and R. Li, "Response of the East Asian climate system to water and heat changes of global frozen soil using NCAR CAM model," Chinese Science Bulletin, vol. 57, no. 34, pp. 4462-4471, 2012.

[13] A. Duan, F. Li, M. Wang, and G. Wu, "Persistent weakening trend in the spring sensible heat source over the Tibetan Plateau and its impact on the Asian summer monsoon," Journal of Climate, vol. 24, no. 21, pp. 5671-5682, 2011.

[14] X. Liu, G. Wu, Y. Liu, and P. Liu, "Diabatic heating over the Tibetan plateau and the seasonal variations of the Asian circulation and summer monsoon onset," Chinese Journal of Atmospheric Sciences, vol. 26, no. 6, pp. 781-793, 2002.

[15] G. Wu, A. Duan, X. Zhang, Y. Liu, and Y. Ma, "Extreme weather and climate changes and its environmental effects over the Tibetan Plateau," Chinese Journal of Nature, vol. 35, pp. 167-171, 2013.

[16] J. Qin, K. Yang, S. Liang, and X. Guo, "The altitudinal dependence of recent rapid warming over the Tibetan Plateau," Climatic Change, vol. 97, no. 1, pp. 321-327, 2009.

[17] B. Pan and J. Li, "Qinghai-Tibetan: a driver and amplifier of the global climatic change-III. The effects of the uplift of Qinghai-Tibetan Plateau on climatic changes," Journal of Lanzhou University, vol. 32, pp. 108-115, 1996.

[18] X. Liu, "Influences of Qinghai-Xizang (Tibet) Plateau uplift on the atmospheric circulation, global climate and environment changes," Plateau Meteorology, vol. 18, pp. 321-332, 1999.

[19] B. Chen, S. Luo, S. Lu, and Y. Zhang, "Simulation and improvement of soil temperature and moisture at Zoige Station in source region of the Yellow River during freezing and thawing," Plateau Meteorology, vol. 33, pp. 337-345, 2014.

[20] B. Chen, S. Luo, S. Lu, and Y. Zhang, "Validation and comparison of the simulation at Zoigê Station during freezing and thawing with Land Surface Model CLM," Climatic and Environmental Research, vol. 19, no. 5, pp. 649-658, 2014.

[21] M. Luo, B. Zhu, and X. Zhang, "The dynamic effect of the Tibetan Plateau on the formation of zonal type circulation over East Asia," Advances in Atmospheric Sciences, vol. 2, no. 2, pp. 158-166, 1985.

[22] Y. Wang, B. Zhang, L. Chen, J. He, W. Li, and H. Chen, "Relationship between the atmospheric heat source over Tibetan Plateau and the heat source and general circulation over East Asia," Chinese Science Bulletin, vol. 53, no. 21, pp. 3387-3394, 2008.

[23] J. Liu and G. Jix, "Spatial-temporal changes of vegetation coverage and its responses to global climate changes in the tibetan plateau," in Proceedings of the International Conference on Environmental Science and Information Application Technology (ESIAT '09), pp. 78-82, Wuhan, China, July 2009.

[24] S. C. Swenson, D. M. Lawrence, and H. Lee, "Improved simulation of the terrestrial hydrological cycle in permafrost regions by the Community Land Model," Journal of Advances in Modeling Earth Systems, vol. 4, no. 3, Article ID M08002, 2012.

[25] S. C. Swenson and D. M. Lawrence, "A new fractional snowcovered area parameterization for the Community Land Model and its effect on the surface energy balance," Journal of Geophysical Research Atmospheres, vol. 117, no. 21, 2012.

[26] R. E. Dickinson, K. W. Oleson, G. Bonan et al., "The community land model and its climate statistics as a component of the community climate system model," Journal of Climate, vol. 19, no. 11, pp. 2302-2324, 2006.

[27] D. M. Lawrence, K. W. Oleson, M. G. Flanner et al., "Parameterization improvements and functional and structural advances in 
version 4 of the Community Land Model," Journal of Advances in Modeling Earth Systems, vol. 3, no. 3, pp. 365-375, 2011.

[28] K. Oleson, D. Lawrence, G. Bonan et al., "Technical description of version 4.0 of the Community Land Model (CLM)," Tech. Rep. NCAR/TN-478+STR, National Center for Atmospheric Research Tech Note, Boulder, Colo, USA, 2010.

[29] Z. M. Subin, W. J. Riley, and D. Mironov, "An improved lake model for climate simulations: model structure, evaluation, and sensitivity analyses in CESM1," Journal of Advances in Modeling Earth Systems, vol. 4, no. 2, pp. 183-204, 2012.

[30] G. B. Bonan, P. J. Lawrence, K. W. Oleson et al., "Improving canopy processes in the Community Land Model version 4 (CLM4) using global flux fields empirically inferred from FLUXNET data," Journal of Geophysical Research, vol. 116, no. 2, pp. 96-101, 2011.

[31] K. Oleson, D. Lawrence, G. Bonan, and Z. Yang, “Technical description of version 4.5 of the Community Land Model (CLM)," Tech. Rep. NCAR/TN-503+STR, National Center for Atmospheric Research Tech Note, Boulder, Colo, USA, 2013.

[32] B. Chen, S. Lu, and S. Luo, "Simulation analysis on land surface process at maqu station in the qinghai-xizang plateau using comminuty land model," Plateau Meteorology, vol. 31, no. 6, pp. 1511-1522, 2012.

[33] X. Wang, M. Yang, G. Pang, G. Wan, and X. Chen, "Simulation and improvement of land surface processes in Nameqie, Central Tibetan Plateau, using the Community Land Model (CLM3.5)," Environmental Earth Sciences, vol. 73, no. 11, pp. 7343-7357, 2014.

[34] J. Xiong, Y. Zhang, S. Wang, L. Shang, Y. Chen, and X. Shen, "Influence of soil moisture transmission scheme improvement in CLM4.0 on simulation of land surface processes in QinghaiXizang Plateau," Plateau Meteorology, vol. 33, pp. 323-336, 2014.

[35] K. Hansson, J. Šimůnek, M. Mizoguchi, L.-C. Lundin, and M. T. van Genuchten, "Water flow and heat transport in frozen soil: numerical solution and freeze-thaw applications," Vadose Zone Journal, vol. 3, no. 2, pp. 693-704, 2004.

[36] L. Shang, Y. Zhang, S. Lü, and S. Wang, "Energy exchange of an alpine grassland on the eastern Qinghai-Tibetan Plateau," Science Bulletin, vol. 60, no. 4, pp. 435-446, 2015.

[37] Z. Li, S. Lyu, Y. Ao, L. Wen, L. Zhao, and S. Wang, "Longterm energy flux and radiation balance observations over Lake Ngoring, Tibetan Plateau," Atmospheric Research, vol. 155, pp. 13-25, 2015.

[38] Y. Pan, S. Lyu, S. Li et al., "Simulating the role of gravel in freeze-thaw process on the Qinghai-Tibet Plateau," Theoretical and Applied Climatology, 2015.

[39] D. Guo, M. Yang, and H. Wang, "Sensible and latent heat flux response to diurnal variation in soil surface temperature and moisture under different freeze/thaw soil conditions in the seasonal frozen soil region of the central Tibetan Plateau," Environmental Earth Sciences, vol. 63, no. 1, pp. 97-107, 2011. 

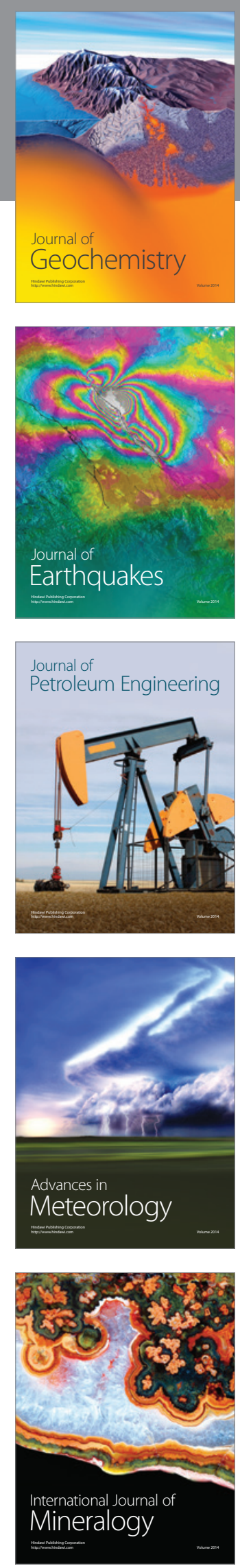
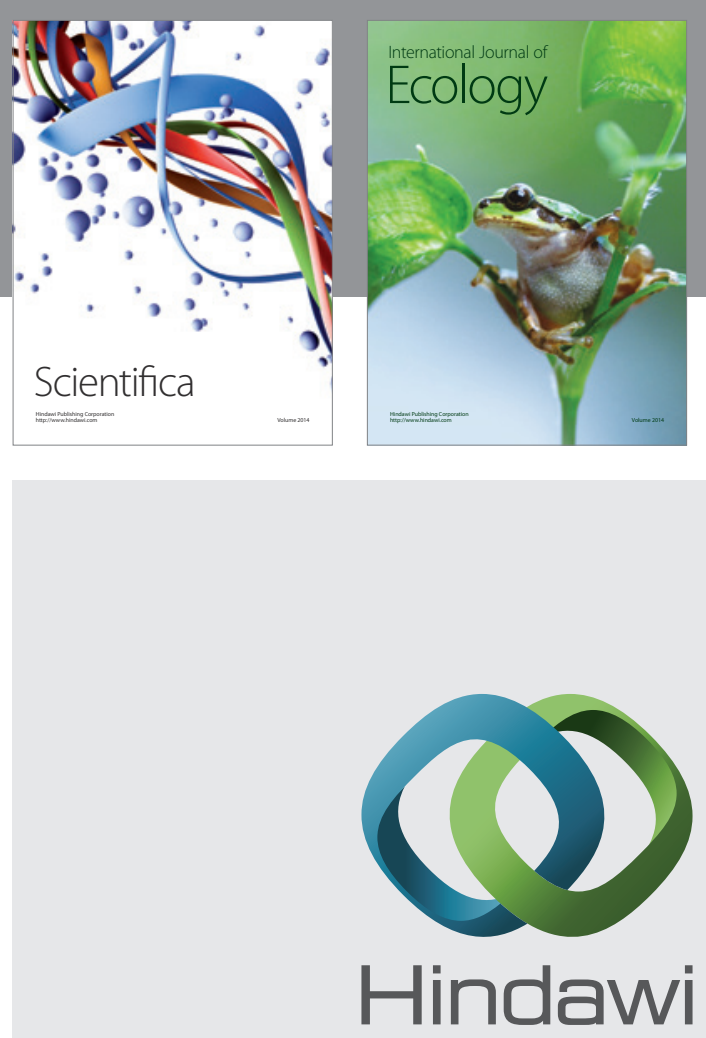

Submit your manuscripts at

http://www.hindawi.com
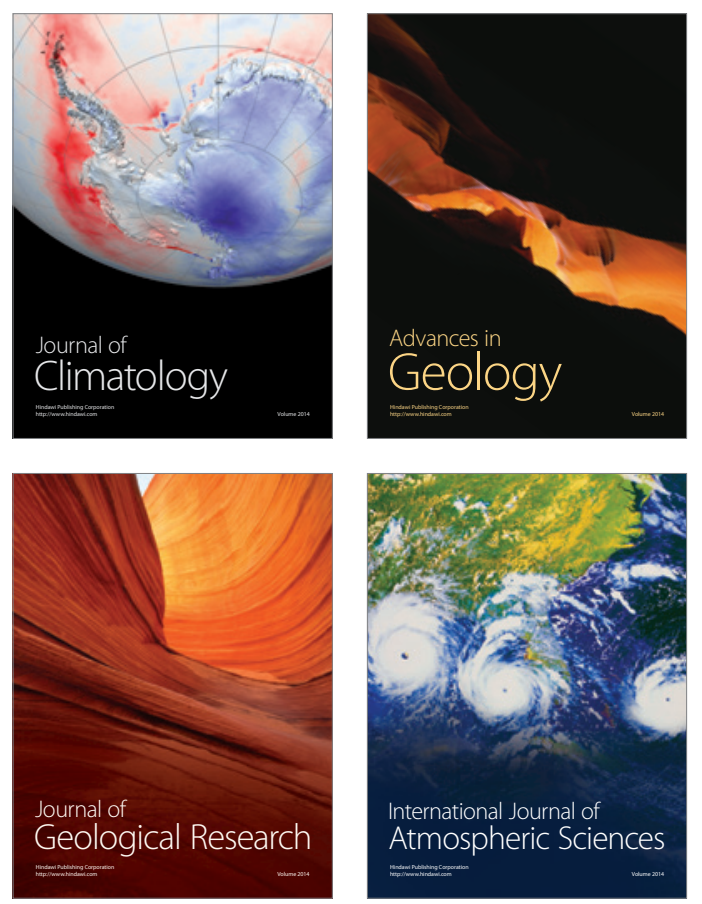

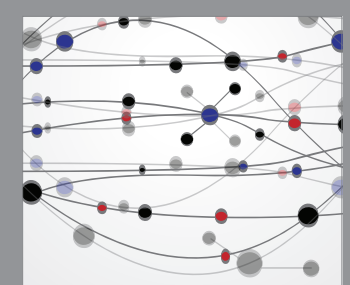

The Scientific

\section{World Journal}
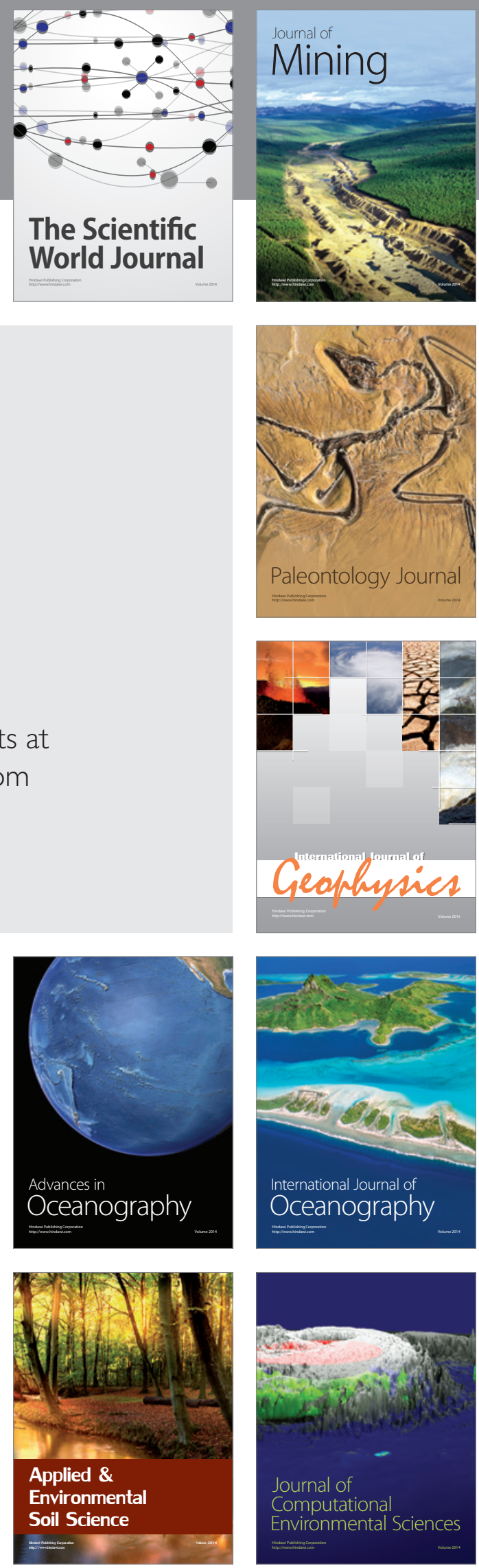